\title{
Antioxidant and UV-radiation absorption activity of aaptamine derivatives - Potential application for natural organic sunscreens
}

Thi Le Anh Nguyen ${ }^{1,2, *}$, Doan Thi Hoai $\mathrm{Nam}^{3}$, Dinh Hieu Truong ${ }^{1,2}$, Nguyen Thi Ai Nhung ${ }^{4}$, Duong Tuan Quang ${ }^{5}$, Dorra Khiri ${ }^{6}$, Sonia Taamalli ${ }^{6}$, Florent Louis ${ }^{6}$, Abderrahman El Bakali ${ }^{6}$ and Duy Quang Dao ${ }^{1, *}$

${ }^{1}$ Institute of Research and Development, Duy Tan University, Da Nang, 550000, Vietnam

${ }^{2}$ Faculty of Natural Sciences, Duy Tan University, Da Nang, 550000, Vietnam

${ }^{3}$ Department of Chemistry, Danang University of Science and Technology - The University of Danang, Da Nang, 550000, Vietnam

${ }^{4}$ Department of Chemistry, University of Sciences, Hue University, Hue, 530000, Vietnam

${ }^{5}$ Department of Chemistry, University of Education, Hue University, Hue, 530000, Vietnam

${ }^{6}$ Université de Lille, CNRS, UMR 8522 - PC2A - PhysicoChimie des Processus de Combustion et de l'Atmosphère, 59000 Lille, France

* Corresponding authors: $\quad$ nguyenthileanh@duytan.edu.vn (T.L.A.N.)

daoduyquang@duytan.edu.vn (D.Q.D.) 


\begin{abstract}
Antioxidant and UV absorption activities of three marine product originated - aaptamine derivatives including piperidine[3,2-b]demethyl(oxy)aaptamine (C1), 9-amino-2-ethoxy-8methoxy-3H-benzo[de][1,6]naphthyridine-3-one $\quad$ (C2), $\quad$ and 2-(sec-butyl)-7,8dimethoxybenzo[de]imidazo[4,5,1-ij][1,6]-naphthyridin-10(9H)-one (C3) were theoretically studied by density functional theory (DFT). Direct antioxidant activities of C1-C3 were firstly evaluated via their intrinsic thermochemical properties and radical scavenging activity of the potential antioxidants with the $\mathrm{HOO}^{\bullet} / \mathrm{HO}^{\bullet}$ radicals via four mechanisms, including: hydrogen atom transfer (HAT), single electron transfer (SET), proton loss (PL) and radical adduct formation (RAF). Kinetic calculation reveals that $\mathrm{HOO}^{\bullet}$ scavenging in water is occurred via HAT mechanism with C1 $\left(k_{\text {app }}, 7.13 \times 10^{6} \mathrm{M}^{-1} \mathrm{~s}^{-1}\right)$ while RAF is more dominant with $\mathbf{C} 2$ ( $k_{\text {app}}$, $\left.1.40 \times 10^{5} \mathrm{M}^{-1} \mathrm{~s}^{-1}\right)$ and $\mathrm{C} 3\left(k_{\mathrm{app}}, 2.90 \times 10^{5} \mathrm{M}^{-1} \mathrm{~s}^{-1}\right)$. Antioxidant activity of aaptamine derivatives can be classified as $\mathbf{C 1}>\mathbf{C} 3>\mathbf{C} 2$. Indirect antioxidant properties based on $\mathrm{Cu}(\mathrm{I})$ and $\mathrm{Cu}(\mathrm{II})$ ions chelating activity were also investigated in aqueous phase. All three studied compounds show spontaneous and favorable $\mathrm{Cu}(\mathrm{I})$ ion chelating activity with $\Delta G^{0}$ being $-15.4,-13.7$, and -15.7 kcal.mol ${ }^{-1}$, whereas $\Delta G^{0}$ for $\mathrm{Cu}(\mathrm{II})$ chelation are $-10.4,-10.8$, and $-2.2 \mathrm{kcal}_{\mathrm{mol}}{ }^{-1}$ for $\mathbf{C 1}, \mathbf{C} 2$ and C3, respectively. In addition, all compounds show UVA and UVB absorption; in which the excitations are determined mostly as $\pi-\pi^{*}$ transition. Overall, the results suggest the potential applications of the aaptamines in pharmaceutics and cosmetics, i.e. as sunscreen and antioxidant ingredient.
\end{abstract}

Keywords: marine product, DFT, aaptamine, antioxidant, free radical scavenging, UV absorption, Cu complexes 


\section{Introduction}

Aaptamines are commonly known marine natural products, which have been extracted from Aaptos aaptos species in the marine milieu of the Pacific ocean, i.e. Malaysia, ${ }^{1}$ Vietnam, ${ }^{2}$ and Indonesia. ${ }^{3}$ The first aaptamine structures, extracted from a Japanese sponge and characterized by Nakamura et al., ${ }^{4}$ are identified as alkaloid-based compounds containing the $1 \mathrm{H}$-benzo[de]1,6-naphthyridine skeleton. There is a large number of research which reported different biological activities of aaptamines such as antifungal, ${ }^{5,6}$ antiviral, ${ }^{7}$ antimicrobial, ${ }^{8}$ and anticancer. ${ }^{1,9-13}$ In particular, antioxidant activity of aaptamines was early predicted and studied. Indeed, aaptamines and isoaaptamine, amongst other marine sponges, were reported for strong antioxidant activity against DPPH radical. ${ }^{14}$ In a perspective view, besides the natural and welldisposed origin, the antioxidant properties and other biological activities of the aaptamines can be of human-health-benefit because that helps protect human body from free radicals, fight aging, boosting the immune system, and prevent diseases. In the modern concept of antioxidant, it is noteworthy that the antioxidant properties of a compound is based not only on the free radical scavenging processes but also on the repairing activity for biomolecules, such as DNA, lipid or proteins, and on the chelating ability with oxidative transition metal ions, particularly $\mathrm{Cu}^{15-19}$ and $\mathrm{Fe}$ ions. ${ }^{20-22}$ The latter plays important role in preventing the indirect formation of reactive hydroxyl radical (i.e. $\mathrm{HO}^{\bullet}$ ) caused by the Fenton-like reactions between $\mathrm{Fe}(\mathrm{II})$ and $\mathrm{Cu}(\mathrm{I})$ with hydrogen peroxide (i.e. $\mathrm{H}_{2} \mathrm{O}_{2}$ ).

On the other hand, oxidative stress (OS) resulting from long-time ultraviolet radiation (UVR) exposure is identified as one of the main causes for skin aging, DNA skin damage and melanogenesis. ${ }^{23}$ At the early stage of the sunscreen research started by the 1940s, most of the products targeted minimizing the effect of UVB $(280-315 \mathrm{~nm})$ radiation because the direct UVB absorption by DNA generates UV-signature mutations leading to DNA lesions and carcinogenic effect. ${ }^{24}$ Scientists later discovered that the UVA (315-400 nm) can deeply penetrate into the skin, producing reactive oxygen species (ROS) and reactive nitrogen species (RNS) in human skin that cause also DNA and other biological molecules to be damaged and so is not less harmful than the UVB to human skin. ${ }^{25,26}$ One of the common mechanism, for example, is the ROS-mediated cell damage by peroxidation of fatty acids within the phospholipid structure of the membrane. Recently, a broad-spectrum UV filter that covers both UVA and UVB regions is one of the first and foremost criteria for considering an organic sunscreen candidate. ${ }^{27}$

Moreover, the photo-protective properties of natural products have been earlier reported for natural antioxidants including polyphenols, ${ }^{28}$ stilbenes, ${ }^{29}$ hydroxycinamate derivatives. ${ }^{30,31} \mathrm{~A}$ large number of studies have shown positive effect of antioxidant in the skin, for both treatment and prevention of inflammation, oxidation, sebaceous glands or melanogenesis. ${ }^{32}$ Multiple mechanisms of skin photo-protective have been documented. ${ }^{26}$ In addition, the synthesis of $p$ hydroxycinnamic diacids such as of ferulic, sinapic, $p$-coumaric and caffeic diacid results in 
molecules which show potent antioxidant and UV filter. ${ }^{33}$ Recently, we reported the antioxidant and photo-protective properties of different natural compounds in which the cycloechinulin and wasabidienone extracted from marine fungus showed the most potential antioxidant and photoprotective properties. ${ }^{34}$

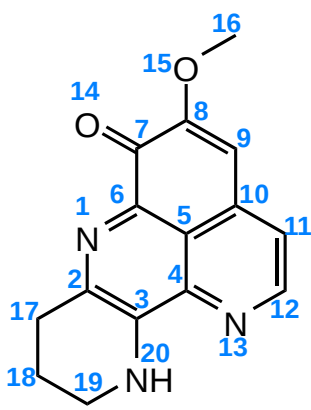

C1

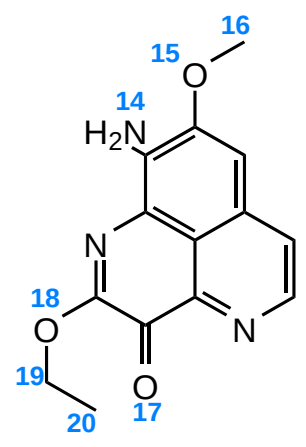

C2

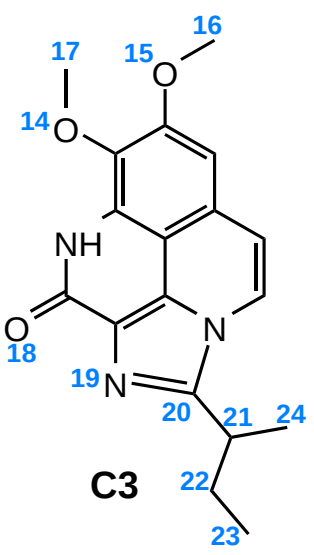

Figure 1: Chemical structure of C1-C3.

To the best of our knowledge, although some experimental studies have been performed on the antioxidant properties of aaptamines derivatives, there have not been any computational studies that consider both radical scavenging and photo-protective properties of the aaptamine derivatives. Thus, in this study the antioxidant activities and the UV filter properties of three aaptamine derivatives ${ }^{4}$ including piperidine[3,2-b]demethyl(oxy)aaptamine (C1), 9-amino-2ethoxy-8-methoxy-3H-benzo[de][1,6]naphthyridine-3-one (C2), and 2-(sec-butyl)-7,8dimethoxybenzo[de]imidazo[4,5,1-ij][1,6]-naphthyridin-10(9H)-one (C3) (Figure 1) were elucidated using density functional theory (DFT). Multi-level thermodynamic and mechanistic approaches were applied to provide better insight into direct antioxidant properties based on the free radical scavenging reactions. Thermodynamic parameters of reaction characteristic of the antioxidant activity of three aaptamines C1-C3 via four common mechanisms: hydrogen transfer (HT), single electron transfer (SET), proton loss (PL), and radical adduct formation (RAF) were focused. Different intrinsic thermochemical parameters including bond dissociation enthalpy (BDE), adiabatic ionization potential (IP) and proton affinity (PA) were calculated in the gas phase (vacuo) and water. The reaction enthalpies $\left(\Delta_{\mathrm{r}} H^{0}\right)$ and standard Gibbs free energies $\left(\Delta_{\mathrm{r}} G^{0}\right)$ of four reactions between the studied compounds and $\mathrm{HOO}^{\bullet}, \mathrm{HO}^{\bullet}$ radicals were examined and the kinetic calculations were investigated using transition state theory (TST). Remarkably, indirect antioxidant properties based on the $\mathrm{Cu}(\mathrm{II})$ ion chelating activity of studied compounds in aqueous phase were also predicted. Finally, the time-dependent density functional theory (TDDFT) was performed to study the UV absorption activities of the aaptamines. Hopefully, the 
obtained results contribute to a better understanding of the antioxidant and UVR absorption properties of marine product which allows further practical applications.

\section{Computational details}

Gaussian 16 revision A.03 package was used to optimize the geometrical and electronic structures of the studied compounds. ${ }^{35}$ All calculations were performed at the M05-2X/6-311+ $+\mathrm{G}(\mathrm{d}, \mathrm{p})$ level of theory. ${ }^{36}$ The M05-2X is previously reported to have a good benefit for the TS location and kinetics calculation. ${ }^{37,38}$

The four main working mechanisms, including formal hydrogen transfer (FHT), single electron transfer (SET), proton loss (PL) and radical adduct formation (RAF) have been investigated. In the first approach, the intrinsic thermochemical parameters characterizing for three mechanisms FHT, SET, and PL were calculated according to the following reaction equations:

+ Formal hydrogen transfer (FHT):

$$
\mathrm{A}-\mathrm{H} \rightarrow \mathrm{A}^{\bullet}+\mathrm{H}^{\bullet}(\mathrm{BDE})
$$

+ Single electron transfer (SET):

$$
\mathrm{A}-\mathrm{H} \rightarrow \mathrm{AH}^{+\bullet}+\mathrm{e}^{-}(\mathrm{IP})
$$

+ Proton transfer (PT):

$$
\mathrm{A}-\mathrm{H} \rightarrow \mathrm{A}^{-}+\mathrm{H}^{+}(\mathrm{PA})
$$

Based on the equations R1-R3, intrinsic thermodynamic parameters such as bond dissociation enthalpies (BDE), adiabatic ionization potential (IP), and proton affinities (PA) were calculated in the gas phase and in water as follows:

$\operatorname{BDE}(\mathrm{A}-\mathrm{H})=H\left(\mathrm{~A}^{\bullet}\right)+H\left(\mathrm{H}^{\bullet}\right)-H(\mathrm{~A}-\mathrm{H})$

$\mathrm{IP}(\mathrm{A}-\mathrm{H})=H\left(\mathrm{AH}^{\bullet+}\right)+H\left(\mathrm{e}^{-}\right)-H(\mathrm{~A}-\mathrm{H})$;

$\mathrm{PA}(\mathrm{A}-\mathrm{H})=H\left(\mathrm{~A}^{-}\right)+H\left(\mathrm{H}^{+}\right)-H(\mathrm{~A}-\mathrm{H})$;

where $H$ accounts for the total energy of the studied species at $298.15 \mathrm{~K}$ and $1 \mathrm{~atm}$. The experimental energy value of the proton $\left(\mathrm{H}^{+}\right)$and the electron $\left(\mathrm{e}^{-}\right)$in gas phase was 1.4811 and $0.7519 \mathrm{kcal} . \mathrm{mol}^{-1}$, respectively. ${ }^{39}$ In water, the energy values of the proton $H\left(\mathrm{H}^{+}\right)$and of electron $H\left(\mathrm{e}^{-}\right)$were -235.3 and $-23.9 \mathrm{kcal} \mathrm{mol}^{-1}$, respectively; calculation method was previously reported. ${ }^{40}$ 
In order to evaluate the influence of chemical nature of free radicals on the antioxidant potential of the studied compounds vs. representative radicals such as $\mathrm{HOO}^{\circ}$, the standard Gibbs free energies of the reaction $\left(\Delta_{\mathrm{r}} G^{0}\right)$ were calculated for HAT, PL, RAF and SET mechanisms according to the R4-R7 reactions (eq.4-eq.7). The $\mathrm{HO}^{\bullet}$ radical scavenging reactions were similarly obtained.

$$
\begin{aligned}
& \text { FHT: } \mathrm{A}-\mathrm{H}+\mathrm{HOO}^{\bullet} \rightarrow \mathrm{A}^{\bullet}+\mathrm{HOOH} ; \\
& \text { PL: A-H }+\mathrm{HOO}^{\bullet} \rightarrow \mathrm{A}^{-}+\mathrm{HOOH}^{\bullet+} ; \\
& \text { RAF: A-H }+\mathrm{HOO}^{\bullet} \rightarrow \mathrm{AH}-\mathrm{OOH}^{\bullet} ; \\
& \text { SET: A-H }+\mathrm{HOO}^{\bullet} \rightarrow \mathrm{AH}^{\bullet+}+\mathrm{HOO}^{-} ;
\end{aligned}
$$

Standard Gibbs free energies $\left(\Delta_{\mathrm{r}} G^{0}\right)$ of the reactions were calculated at $298.15 \mathrm{~K}$ as follows:

$$
\begin{aligned}
& \Delta_{\mathrm{r}} G^{0}(\mathrm{HAT})=\left[G\left(\mathrm{~A}^{\bullet}\right)+G(\mathrm{HOOH})\right]-\left[G(\mathrm{~A}-\mathrm{H})+G\left(\mathrm{HOO}^{\bullet}\right)\right] \\
& \Delta_{\mathrm{r}} G^{0}(\mathrm{PL})=\left[G\left(\mathrm{~A}^{-}\right)+G\left(\mathrm{HOOH}^{\bullet+}\right)\right]-\left[G(\mathrm{~A}-\mathrm{H})+G\left(\mathrm{HOO}^{\bullet}\right)\right] ; \\
& \Delta_{\mathrm{r}} G^{0}(\mathrm{RAF})=G\left(\mathrm{AH}-\mathrm{OOH}^{\bullet}\right)-G(\mathrm{~A}-\mathrm{H})-G\left(\mathrm{HOO}^{\bullet}\right) ; \\
& \Delta_{\mathrm{r}} G^{0}(\mathrm{SET})=\left[G\left(\mathrm{AH}^{\bullet+}\right)+G(\mathrm{HOO})\right]-\left[G\left(\mathrm{HOO}^{\bullet}\right)+G(\mathrm{~A}-\mathrm{H})\right]
\end{aligned}
$$

The kinetics of FHT and RAF reactions in the gas phase and the water studied in this work were based on quantum mechanics-based test for overall free radical scavenging activity (QM-ORSA) protocol $^{37}$ using the Eyringpy code. ${ }^{41}$ Details of this calculation can be found in our previous work. ${ }^{34}$ In brief, reaction rate, $k(\mathrm{~T})$, can be calculated using conventional transition state theory (TST) approach.

$$
k(T)=\sigma K \frac{k_{B} T}{h} e^{\frac{-\Delta G^{\ddagger}}{R T}} ;
$$

where $\Delta G^{\ddagger}$ is the Gibbs free energy of activation; $T$ is the temperature in Kelvin; $k_{\mathrm{B}}$ is the Boltzmann constant and $h$ is the Planck constant; $\sigma$ is the reaction symmetry number (or the reaction path degeneracy), $\kappa$ is the transmission coefficient attributing for the quantum tunneling effects by employing Eckart barrier. The solvent cage effect was included according to the correction proposed by Okuno, ${ }^{42}$ taking into account the free volume theory. ${ }^{43}$

For SET reaction, the Marcus theory ${ }^{44}$ was applied for the estimation of the electron transfer rate. The energy barrier was obtained as eq. 9 .

$$
\Delta G_{S E T}^{\ddagger}=\frac{\lambda}{4}\left(1+\frac{\Delta G_{S E T}^{0}}{\lambda}\right)^{2} ;
$$


where $\Delta G_{\text {SET }}^{0}$ is the free energy of reaction; $\lambda$ is the nuclear reorganization energy which can be calculated by the difference of $\Delta E_{\mathrm{SET}}$ and $\Delta G_{\mathrm{SET}}^{0}$, with $\Delta E_{\mathrm{SET}}$ is the vertical energy between reactants and products of the reaction via SET mechanism.

In solvent, diffusion rate $k_{\mathrm{D}}$ may be important and greatly contributes to the apparent rate constant $k_{\text {app }}$. Therefore, the Collins-Kimball theory ${ }^{45}$ was employed (eq.10).

$k_{\mathrm{app}}=k_{\mathrm{D}} \cdot k /\left(k_{\mathrm{D}}+k\right)$;

where $\mathrm{k}$ is the thermal rate constant and $k_{\mathrm{D}}$ is the diffusion rate constant calculated following Smoluchowski ${ }^{46}$ (eq.11).

$k_{\mathrm{D}}=4 \pi R_{\mathrm{AB}} D_{\mathrm{AB}} N_{\mathrm{A}} ;$

where the $\mathrm{R}_{\mathrm{AB}}$ is the reactant distance, $\mathrm{D}_{\mathrm{AB}}$ is the mutual diffusion coefficient of the antioxidant $A$ and radical $\mathrm{B}\left(\mathrm{HOO}^{\circ}\right)$ and $\mathrm{NA}$ is the Avogadro number; $\mathrm{D}_{\mathrm{AB}}$ is estimated from $\mathrm{D}_{\mathrm{A}}$ and $\mathrm{D}_{\mathrm{B}}$ as proposed by Truhlar $^{47}$ in which $\mathrm{D}_{\mathrm{A}}$ and $\mathrm{D}_{\mathrm{B}}$ are computed using the Stockes-Einstein approach ${ }^{48,49}$ (eq.12)

$\mathrm{D}_{\mathrm{AB}}=k_{\mathrm{B}} \cdot \mathrm{T} /(6 \pi \eta \mathrm{r})$;

in which $\eta$ is the viscosity of water $\left(8.91 \times 10^{-4} \mathrm{P} . \mathrm{s}\right)$ and $r$ is the radius of the solute.

The $p \mathrm{~K}_{\mathrm{a}}$ calculation of three amines was performed following the thermodynamic cycle previously reported. ${ }^{50,51} p \mathrm{~K}_{\mathrm{a}}$ of the $\mathbf{C 1 - C 3}$ were determined as (eq.13)

$p \mathrm{~K}_{\mathrm{a}}=\Delta G_{\text {deprot,aq }}^{0} / \mathrm{RT} \ln (10) ;$

where the $\Delta G_{\text {deprotaq }}^{0}$ is the solution-phase standard free energy of deprotonation.

$\mathrm{Cu}(\mathrm{I})$ and $\mathrm{Cu}(\mathrm{II})$ ions chelating processes of three antioxidant compounds, now denoted as $\mathrm{L}$, occur via the following reactions:

$$
\begin{aligned}
& \mathrm{L}+\left[\mathrm{Cu} .4 \mathrm{H}_{2} \mathrm{O}\right]^{+}=\left[\mathrm{CuL} .2 \mathrm{H}_{2} \mathrm{O}\right]^{+}+2 \mathrm{H}_{2} \mathrm{O} ; \\
& \mathrm{L}+\left[\mathrm{Cu} .4 \mathrm{H}_{2} \mathrm{O}\right]^{2+}=\left[\mathrm{CuL} .2 \mathrm{H}_{2} \mathrm{O}\right]^{2+}+2 \mathrm{H}_{2} \mathrm{O} ;
\end{aligned}
$$

The Gibbs free energies $\left(\Delta_{\mathrm{r}} G^{0}\right)$ of the complex formation were then calculated by (eq.14) and (eq.15) as follows:

$\Delta_{\mathrm{r}} G^{0}[\mathrm{Cu}(\mathrm{I})]=G\left(\left[\mathrm{CuL} .2 \mathrm{H}_{2} \mathrm{O}\right]^{+}\right)+2 G\left(\mathrm{H}_{2} \mathrm{O}\right)-G(\mathrm{~L})-G\left(\left[\mathrm{Cu} \cdot 4 \mathrm{H}_{2} \mathrm{O}\right]^{+}\right) ;$

$\Delta_{\mathrm{r}} G^{0}[\mathrm{Cu}(\mathrm{II})]=G\left(\left[\mathrm{CuL} .2 \mathrm{H}_{2} \mathrm{O}\right]^{2+}\right)+2 G\left(\mathrm{H}_{2} \mathrm{O}\right)-G(\mathrm{~L})-G\left(\left[\mathrm{Cu} .4 \mathrm{H}_{2} \mathrm{O}\right]^{2+}\right) ; \quad$ (eq.14)

The standard enthalpies of reaction $\left(\Delta H^{0}\right)$ were similarly calculated for the complexation reaction (R8) and (R9). 
The vertical excitation of C1-C3 in methanol was calculated using TD-DFT approach. A small benchmark of functionals with different exchange correlation XC part, i.e. B3LYP, B98, M06, PBE0, CAMB3LYP, and M05-2X were employed with the same basis set as in the previous part. These functionals are chosen following the recommendation by Jacquemine et al. for low Mean signed Error (MSE) and Mean absolute Error (MAE) for singlet excited states. ${ }^{52}$ Solvent effects were implicitly studied using the Polarization Continuum Model (IEF-PCM). ${ }^{53}$

\section{Results and Discussion}

\subsection{Structure and electronic properties}

The optimized structures and electronic properties of the three studied aaptamine compounds calculated by DFT method at the M05-2X/6-311++G(d,p) level of theory in the gas phase (Figure 2).

Compounds C1-C3 share the benzo[de][1,6]naphthyridine skeleton and similarly have $-\mathrm{OCH}_{3}$ group attached to $\mathrm{C} 8$ position. At $\mathrm{C} 7$, the substituent groups such as ketone $(=\mathrm{O})$, amine $\left(-\mathrm{NH}_{2}\right)$ and methoxy $\left(-\mathrm{OCH}_{3}\right)$ are attached to the $\mathrm{B}$ ring, in $\mathbf{C 1}, \mathbf{C} \mathbf{2}$ and $\mathbf{C 3}$, respectively. The main difference in the chemical nature of three compounds is the substituent groups found at the $\mathrm{A}$ ring, for $\mathbf{C 1}$ a N-containing six-membered cycle, for $\mathbf{C} 2$ the $=\mathrm{O}$ and $-\mathrm{OC}_{2} \mathrm{H}_{5}$ groups, and for $\mathbf{C} \mathbf{3}$ a $\mathrm{N}$-containing five-membered cycle with 2-butyl derivative that shared both $\mathrm{A}$ and $\mathrm{C}$ ring. Moreover, the electronic distribution on the frontier molecular orbitals such as the highest occupied molecular orbital (HOMO) and the lowest unoccupied molecular orbital (LUMO) shows that all the rings play a key role in electron-donating (HOMO distribution) and electronaccepting (LUMO distribution) reactions with free radicals. For all molecules, the electrostatic potential (ESP) maps display a negative region on the $\mathrm{C}=\mathrm{O}$ groups and the nearby carbons. 


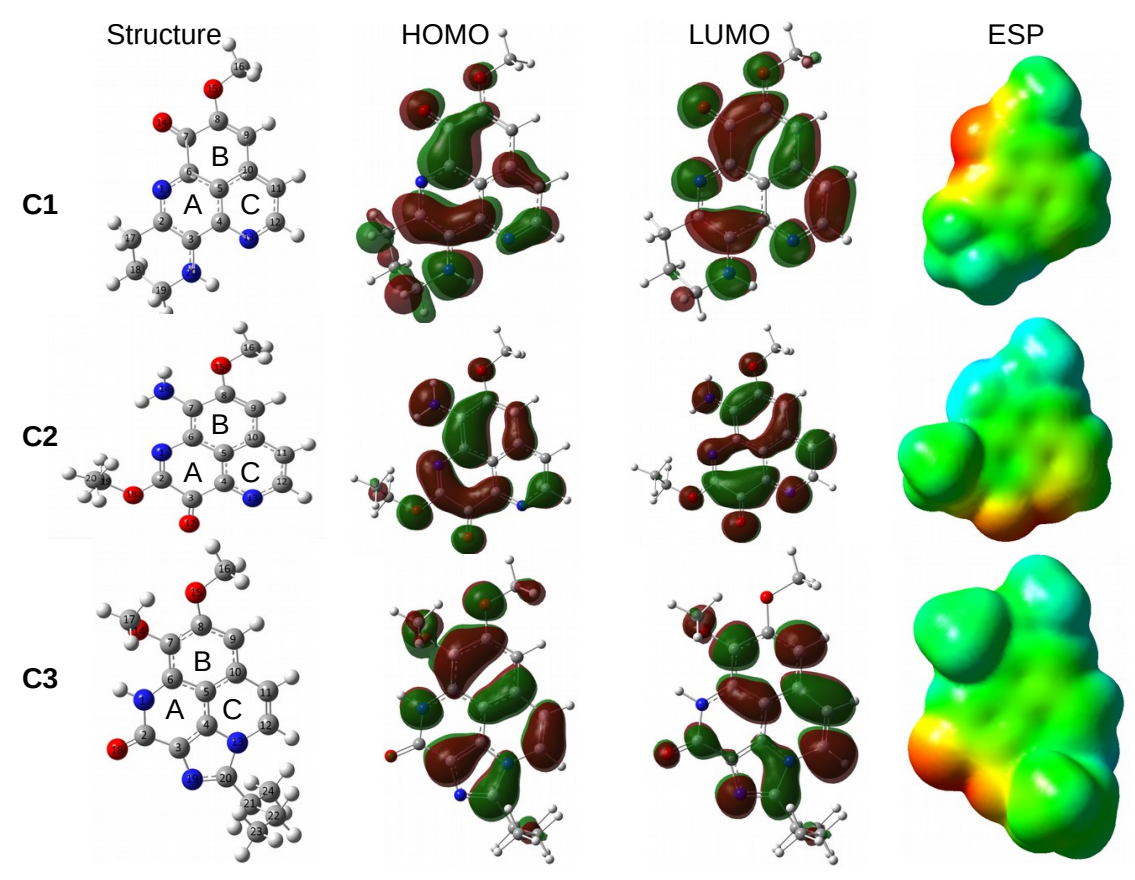

Figure 2: Optimized geometry, HOMO, LUMO, and ESP maps of C1-C3 calculated in the gas phase at the M05-2X/6-311++G(d,p) level of theory (isovalue $=0.02$ ).

\subsection{Evaluation of antioxidant potential via intrinsic thermochemical parameters}

Table 1 presents the intrinsic thermochemical parameters such as BDE, IP and PA which are examined via the FHT (R1), SET (R2) and PL (R3) mechanisms, respectively.

The most favorable $\mathrm{H}$ donating positions for $\mathbf{C 1}$ and $\mathbf{C 3}$ are found at $\mathrm{C}-\mathrm{H}$ bonds. For example, the $\mathbf{C 1}$ exhibits the lowest BDE at C17 and C19 positions, being 85.5 and $85.7 \mathrm{kcal} \mathrm{mol}^{-1}$, respectively, whereas $\mathrm{C} 3$ has the lowest $\mathrm{BDE}$ value at $\mathrm{C} 21$ position, i.e. $84.6 \mathrm{kcal} \mathrm{mol}^{-1}$. For $\mathbf{C 2}$, the easiest breaking-bond characterized by the lowest BDE value is located at N14 position (92.4 $\mathrm{kcal} \mathrm{mol}^{-1}$ ). It is noteworthy that BDE values of $\mathbf{C 1}$ and $\mathbf{C 3}$ are much lower than that of the standard antioxidant Trolox in the gas phase (i.e. $91.1 \mathrm{kcal} \mathrm{mol}^{-1}$ ). ${ }^{54}$ Consequently, the antioxidant potential of these aaptamines via FHT process can be classified in the following order: $\mathbf{C} 2<$ Trolox $<\mathbf{C 1}<\mathbf{C 3}$. We observed a very slight change of BDE values in water for all compounds C1-C3. This result is not unexpectedly taken into account the neutral nature of the $\mathrm{H}$ atom species that is transferred. The only exception is obtained for $\mathbf{C} 1$ at $\mathrm{C} 19$ position, with a BDE value lowering from $85.7 \mathrm{kcal} \mathrm{mol}^{-1}$ in gas phase to $79.7 \mathrm{kcal} \mathrm{mol}^{-1}$ in water.

The proton donating reaction from the aaptamines to free radical is characterized by the proton affinity (PA, eq.3); the lower the PA value, the better the antioxidant potential. As can be seen in Table 1, the lowest PA values are found to be 342.5, 343.5 and $347.2 \mathrm{kcal} \mathrm{mol}^{-1}$ for C1 (at C20 position), C2 (at N14 position) and C3 (at N1 position), respectively. These PA values are quite 
similar to that of cembrene in the gas phase (i.e. $343.2 \mathrm{kcal} \mathrm{mol}^{-1}$ ). The proton donating ability of the three compounds in reaction with free radical according to the PL process is in the increasing order: C3 $<$ cembrene $\approx \mathbf{C} \mathbf{2}<\mathbf{C 1}$. It is noteworthy that the PL is much preferred in water, for which the PA values are significantly reduced about $60 \mathrm{kcal} \mathrm{mol}^{-1}$. The result is totally in agreement with the nature of the charge specie that is given and with previously reported results. ${ }^{55}$

Ionization potential (IP), characteristic for SET mechanism, is the minimum energy required to transfer an electron from the studied compound to free radical to form cationic species at ground state. The lower the IP value, the easier the electron transferring ability, thus, the antioxidant activity via SET mechanism will be higher. According to the results presented in Table 1, the adiabatic IP of C1-C3 varied from 168 to $169 \mathrm{kcal} \mathrm{mol}^{-1}$, which is slightly higher than that of Trolox (i.e. $164.6 \mathrm{kcal}^{\mathrm{mol}}{ }^{-1}$ ) and lower than the one of cembrene (i.e. $171.9 \mathrm{kcal} \mathrm{mol}^{-1}$ ). ${ }^{54}$ The antioxidant activities of the studied aaptamines following the SET mechanism increases in the order: Trolox $<\mathbf{C 2}<\mathbf{C 1}<\mathbf{C} 3<$ cembrene. Similar to the proton transfer, the electron transfer is also favorable in water, with IP values reducing from 168-169 $\mathrm{kcal} \mathrm{mol}^{-1}$ in gas phase to 109-114 $\mathrm{kcal} \mathrm{mol}^{-1}$ in water, while remaining in the same order $\mathbf{C} \mathbf{2}<\mathbf{C} \mathbf{1}<\mathbf{C} 3$.

Overall, three aaptamines C1-C3 are potential antioxidants. In the gas phase, the FHT mechanism can be responsible for the antioxidant properties of the molecules while in water the PL mechanism is particularly favorable.

Table 1: BDE, PA and adiabatic IP values (in kcal mol ${ }^{-1}$ ) of the C1-C3 calculated in the gas phase at the M05-2X/6-311++G(d,p) level of theory. Corresponding values in water are given in parentheses.

\begin{tabular}{|c|c|c|c|c|c|c|c|c|c|c|c|}
\hline \multicolumn{4}{|c|}{ C1 } & \multicolumn{4}{|c|}{ C2 } & \multicolumn{4}{|c|}{ C3 } \\
\hline Pos. & BDE & PA & IP & Pos. & BDE & PA & IP & Pos & BDE & PA & IP \\
\hline C9 & 111.8 & 371.6 & \multirow{10}{*}{$\begin{array}{r}168.6 \\
(110.0)\end{array}$} & C9 & 113.9 & 366.7 & \multirow{10}{*}{$\begin{array}{c}168.3 \\
(109.2)\end{array}$} & C9 & 113.7 & 368.9 & \multirow{10}{*}{$\begin{array}{r}169.3 \\
(114.0\end{array}$} \\
\hline C11 & 114.3 & 374.4 & & C11 & 113.5 & 376.3 & & C11 & 114.9 & 371.3 & \\
\hline C12 & 106.2 & 383.6 & & C12 & 107.3 & 387.6 & & C12 & 114.4 & 360.6 & \\
\hline C16 & 97.1 & 367.1 & & C16 & 97.6 & 384.4 & & C16 & 96.5 & 384.2 & \\
\hline C17 & $\begin{array}{c}85.5 \\
(85.6)\end{array}$ & 366.4 & & C19 & 94.7 & 377.8 & & C17 & 97.3 & 389.3 & \\
\hline C18 & 98.9 & 390.7 & & C20 & 100.8 & & & C21 & $\begin{array}{c}84.6 \\
(84.9) \\
\end{array}$ & 366.3 & \\
\hline C19 & $\begin{array}{c}85.7 \\
(79.7) \\
\end{array}$ & 361.7 & & N14 & $\begin{array}{c}92.4 \\
(91.6) \\
\end{array}$ & $\begin{array}{l}343.5 \\
(59.6) \\
\end{array}$ & & C22 & 95.6 & 396.0 & \\
\hline \multirow[t]{3}{*}{ C20 } & 93.2 & $\begin{array}{l}342.5 \\
(60.2)\end{array}$ & & & & & & C23 & 99.8 & 360.7 & \\
\hline & & & & & & & & C24 & 99.0 & 390.4 & \\
\hline & & & & & & & & N1 & 101.8 & $\begin{array}{l}347.2 \\
\text { (59.7) }\end{array}$ & \\
\hline
\end{tabular}

3.3. $\mathrm{HOO}^{\bullet}$ and $\mathrm{HO}^{\bullet}$ free radical scavenging 
The antioxidant potential of the studied aaptamines is investigated through the interactions with two representative free radicals, $\mathrm{HOO}^{\bullet}$ and $\mathrm{OH}^{\bullet}$, via four distinguished processes: formal hydrogen transfer (FHT), proton loss (PL), radical adduct formation (RAF), and single electron transfer (SET) mechanism (R4 -R7). The Gibbs free energies $\left(\Delta_{\mathrm{r}} G^{0}\right)$ of HAT, PL and RAF reactions between antioxidant and $\mathrm{HOO}^{\circ}$ and $\mathrm{HO}^{\bullet}$ radicals at various positions are shown in Table 2 and Table 3, respectively. The reaction via SET mechanism, which is considered position-independent, is separately presented in Table 4.

Table 2: Gibbs free energy $\left(\Delta_{\mathrm{r}} G^{0}\right.$, $\left.\mathrm{kcal} \mathrm{mol}^{-1}\right)$ at $298.15 \mathrm{~K}$ of the HAT, PL, and RAF reaction of C1-C3 towards $\mathrm{HOO}^{\bullet}$ radical in the gas phase. Corresponding values calculated in water are given in parentheses for the most spontaneous reactions only. All calculations are performed at the M05-2X/6-311++G(d,p) level of theory.

\begin{tabular}{|c|c|c|c|c|c|c|c|c|c|c|c|}
\hline \multicolumn{4}{|c|}{ HAT } & \multicolumn{4}{|c|}{ PL } & \multicolumn{4}{|c|}{ RAF } \\
\hline Pos. & C1 & C2 & $\mathrm{C3}$ & Pos. & C1 & C2 & C3 & Pos. & $\mathrm{C1}$ & $\mathrm{C} 2$ & C3 \\
\hline C9 & 27.3 & 29.5 & 29.2 & C9 & 219.8 & 214.9 & 217.0 & C2 & -1.0 & $\begin{array}{l}-9.8 \\
(5.2)\end{array}$ & - \\
\hline C11 & 29.8 & 29.0 & 30.5 & C11 & 222.5 & 224.5 & 219.4 & C3 & -7.8 & 10.3 & 7.9 \\
\hline C12 & 21.7 & 22.8 & 29.9 & C12 & 231.8 & 235.7 & 208.7 & C4 & 14.4 & 2.4 & 2.6 \\
\hline C16 & 12.7 & 13.1 & 12.0 & C16 & 224.3 & 232.5 & 232.3 & C5 & 19.8 & 19.6 & 11.0 \\
\hline C17 & $\begin{array}{c}1.0 \\
(0.4)\end{array}$ & & 12.8 & C17 & 214.5 & & 237.5 & C6 & -3.6 & 0.1 & 9.6 \\
\hline C18 & 14.4 & & & C18 & 238.9 & & & C7 & - & -5.6 & -7.4 \\
\hline C19 & $\begin{array}{c}1.2 \\
(-5.0)\end{array}$ & $\begin{array}{l}10.2 \\
(9.1)\end{array}$ & & C19 & 209.9 & 225.9 & & C8 & $\begin{array}{c}-12.6 \\
(6.5)\end{array}$ & -1.5 & 3.7 \\
\hline C20 & 8.7 & 16.4 & & C20 & $\begin{array}{l}190.6 \\
(77.3) \\
\end{array}$ & & & C9 & -6.1 & 7.0 & -0.3 \\
\hline N14 & & $\begin{array}{c}7.9 \\
(7.1)\end{array}$ & & N14 & & $\begin{array}{l}191.7 \\
(77.5)\end{array}$ & & C10 & 8.3 & 16.5 & 9.8 \\
\hline N1 & & & 17.4 & N1 & & & $\begin{array}{l}195.3 \\
(76.8)\end{array}$ & C11 & -4.0 & -4.3 & -1.4 \\
\hline C21 & & & $\begin{array}{c}0.2 \\
(-0.4) \\
\end{array}$ & C21 & & & 214.4 & C12 & 0.4 & 3.4 & $\begin{array}{l}-11.7 \\
(3.0) \\
\end{array}$ \\
\hline C22 & & & 11.1 & C22 & & & 244.1 & & & & \\
\hline C23 & & & 15.4 & C23 & & & 208.9 & & & & \\
\hline C24 & & & 14.5 & C24 & & & 239.0 & & & & \\
\hline
\end{tabular}

As shown in the Table 2, in the gas phase, the Gibbs free energy values $\left(\Delta_{\mathrm{r}} G^{0}\right)$ for FHT reaction (R4) towards $\mathrm{HOO}^{\bullet}$ are positive at all $\mathrm{H}$-donating positions, ranging from 0.2 to $30.5 \mathrm{kcal} \mathrm{mol}^{-1}$. This result indicates that the potential for $\mathrm{HOO}^{\bullet}$ removal via FHT mechanism of all three investigated compounds is not spontaneous and not favorable. Concerning the RAF mechanism (R6), the $\Delta_{\mathrm{r}} G^{0}$ found negative values at some specific positions. For example, the $\mathbf{C} \mathbf{1}$ compound shows highly negative $\Delta_{\mathrm{r}} G^{0}$ of -13.0 and $-12.6 \mathrm{kcal} \mathrm{mol}^{-1}$ at C7 and C8 positions, respectively. For C2, HOO RAF process is highly favorable at C2 position with $\Delta_{\mathrm{r}} G^{0}$ being $-9.8 \mathrm{kcal} \mathrm{mol}^{-1}$. 
Finally, for C3, the RAF reaction favorably occurs at C2 and C12 positions with $\Delta_{\mathrm{r}} G^{0}$ value being -14.2 and $-11.7 \mathrm{kcal} \mathrm{mol}^{-1}$, respectively. Thus, the RAF is the only responsible mechanism for the scavenging process towards $\mathrm{HOO}^{\bullet}$ radical in the gas phase. However, in water, $\mathrm{HOO}^{\bullet}$ scavenging is only favorable with FHT mechanism but not with RAF. Indeed, spontaneous $\Delta_{\mathrm{r}} G^{0}$ are only obtained via FHT mechanism for C1 (at C19 position, $-0.5 \mathrm{kcal} \mathrm{mol}^{-1}$ ) and C3 (at C21 position, $-0.4 \mathrm{kcal} \mathrm{mol}^{-1}$ ). Finally, the proton transferring process (PL, R5) has positive $\Delta_{\mathrm{r}} G^{0}$ at all positions; thus, the ability to remove $\mathrm{HOO}^{\bullet}$ free radicals by PL process is neither favored in the gas phase nor in water.

Table 3: Gibbs free energy $\left(\Delta_{\mathrm{r}} G^{0}, \mathrm{kcal} \mathrm{mol}^{-1}\right)$ at $298.15 \mathrm{~K}$ of the FHT, PL, and RAF reaction of C1-C3 towards $\mathrm{HO}^{\bullet}$ radical in the gas phase. Corresponding values calculated in water are only given (in parentheses) for the most spontaneous reactions. All calculations are performed at the M05-2X/6-311++G(d,p) level of theory.

\begin{tabular}{|c|c|c|c|c|c|c|c|c|c|c|c|}
\hline \multicolumn{4}{|c|}{ HAT } & \multicolumn{4}{|c|}{ PL } & \multicolumn{4}{|c|}{ RAF } \\
\hline Pos. & C1 & C2 & C3 & Pos. & $\mathrm{C1}$ & C2 & C3 & Pos. & C1 & C2 & C3 \\
\hline C9 & -4.4 & -2.3 & -2.6 & C9 & 437.0 & 432.1 & 434.3 & $\mathrm{C} 2$ & & $\begin{array}{c}-39.3 \\
(-23.6) \\
\end{array}$ & - \\
\hline C11 & -1.9 & -2.7 & -1.3 & C11 & 439.8 & 441.7 & 436.6 & C3 & -33.0 & -16.3 & -7.9 \\
\hline C12 & -10.0 & -8.9 & -1.9 & C12 & 449.0 & 453.0 & 425.9 & C4 & -9.8 & -21.7 & -10.4 \\
\hline C16 & -19.1 & -18.6 & -19.7 & C16 & 441.5 & 449.7 & 449.5 & C5 & -4.2 & -3.3 & -2.5 \\
\hline C17 & $\begin{array}{c}-30.7 \\
(-33.6) \\
\end{array}$ & & -18.9 & C17 & 431.8 & & 454.7 & C6 & -28.1 & -23.2 & -4.5 \\
\hline C18 & -17.3 & & & C18 & 456.1 & & & C7 & -17.8 & -32.1 & $\begin{array}{c}-26.7 \\
(-24.6) \\
\end{array}$ \\
\hline C19 & $\begin{array}{c}-30.5 \\
(-38.9)\end{array}$ & $\begin{array}{c}-21.6 \\
(-24.8)\end{array}$ & & C19 & 427.1 & 443.1 & & C8 & $\begin{array}{c}-41.6 \\
(-21.6)\end{array}$ & -27.7 & -16.1 \\
\hline C20 & -23.0 & -15.4 & & C20 & $\begin{array}{r}407.9 \\
(79.7)\end{array}$ & & & C9 & -31.6 & -32.2 & -15 \\
\hline N14 & & $\begin{array}{c}-23.8 \\
(-26.8)\end{array}$ & & N14 & & $\begin{array}{r}408.9 \\
(80.0) \\
\end{array}$ & & C10 & -15.0 & -5.7 & -2.1 \\
\hline N1 & & & -14.4 & N1 & & & $\begin{array}{r}412.5 \\
(79.2)\end{array}$ & C11 & -30.7 & -30.7 & -16.6 \\
\hline C21 & & & $\begin{array}{c}-31.6 \\
(-34.4)\end{array}$ & C21 & & & 431.7 & C12 & -24.0 & -20.4 & $\begin{array}{c}-26.6 \\
(-24.2) \\
\end{array}$ \\
\hline C22 & & & -20.6 & C22 & & & 461.3 & & & & \\
\hline C23 & & & -16.4 & C23 & & & 426.1 & & & & \\
\hline C24 & & & -17.3 & C24 & & & 456.3 & & & & \\
\hline
\end{tabular}

Regarding to the $\mathrm{OH}^{\bullet}$ scavenging activities (Table 3), the negative $\Delta_{\mathrm{r}} G^{0}$ values are obtained at all positions of three studied compounds for both the FHT and RAF processes. This proves that C1-C3 have high scavenging potential towards $\mathrm{OH}^{\bullet}$ radical via FHT and RAF processes. The most active compound via FHT mechanism is awarded for C1 (C17 position) and C3 (C21 
position), with the $\Delta_{\mathrm{r}} G^{0}$ of -30.7 and $-31.6 \mathrm{kcal} \mathrm{mol}^{-1}$, respectively. The lowest $\Delta_{\mathrm{r}} G^{0}$ values for RAF mechanism are obtained for C1 (C8 position) and C2 (C2 position) compounds with the values in the gas phase of -41.6 and $-39.3 \mathrm{kcal} \mathrm{mol}^{-1}$, respectively. For the proton transfer process, the positive value of $\Delta_{\mathrm{r}} G^{0}$ is observed at all the positions for all aaptamines. This result is reasonable because the gas phase is not a favorable medium for the charge transferring process like the proton transfer. In gas phase, the RAF scavenging towards $\mathrm{OH}^{\bullet}$ is more favorable than the FHT. For example, $\mathbf{C} 1$ has the lowest $\Delta_{\mathrm{r}} G^{0}(\mathrm{FHT})$ being $-30.7 \mathrm{kcal} \mathrm{mol}^{-1}$, whereas it has the lowest $\Delta_{\mathrm{r}} G^{0}$ (RAF) being $-41.6 \mathrm{kcal} \mathrm{mol}^{-1}$. In contrast, in water, the HAT is more competitive than the RAF. For example, the lowest $\Delta_{\mathrm{r}} G^{0}(\mathrm{FHT})$ of $\mathbf{C 1}$ is lowered to $-38.9 \mathrm{kcal} \mathrm{mol}^{-1}$ at $\mathrm{C} 19$, while the lowest $\Delta_{\mathrm{r}} G^{0}(\mathrm{RAF})$ is obtained with $\mathbf{C} 3$ with $-24.6 \mathrm{kcal} \mathrm{mol}^{-1}$ at $\mathrm{C} 18$ position. In contract to this, the PL process is always not spontaneous and not favorable in any medium.

Moreover, the Gibbs free energies of the SET reactions (R7) are not favorable in our conditions with the $\Delta_{\mathrm{r}} G^{0}$ value in the gas phase varying around $145 \mathrm{kcal} \mathrm{mol}^{-1}$ for $\mathrm{HOO}^{\bullet}$ radical and 130 kcal mol${ }^{-1}$ for $\mathrm{HO}^{\bullet}$ radical (Table 4). Although the $\Delta_{\mathrm{r}} G^{0}$ have been significantly decreased in water (15-41 kcal mol$\left.{ }^{-1}\right)$, the electron transfer is obviously not favorable.

Table 4: Gibbs free energy $\left(\Delta_{\mathrm{r}} \mathrm{G}^{0}\right.$, $\left.\mathrm{kcal} \mathrm{mol}^{-1}\right)$ at $298.15 \mathrm{~K}$ of SET reaction towards $\mathrm{HOO} / \mathrm{HO}^{\bullet}$ free radical

\begin{tabular}{|c|c|c|c|c|c|c|}
\hline \multirow{2}{*}{} & \multicolumn{3}{|c|}{ HOO` $^{\bullet}$} & \multicolumn{3}{c|}{ HO` $^{\bullet}$} \\
\cline { 2 - 7 } & C1 & C2 & C3 & C1 & C2 & C3 \\
\hline Gas & 145.1 & 144.8 & 145.5 & 129.7 & 129.5 & 130.2 \\
\hline Water & 37.4 & 37.2 & 41.1 & 15.3 & 15.2 & 19.0 \\
\hline
\end{tabular}

Overall, the radical scavenging activities of the studied compounds favorably occur via RAF mechanism in the gas phase while in water it more likely occurs via HAT mechanism. The HO• radical scavenging is much more favorable than the reaction with $\mathrm{HOO}^{\circ}$. Finally, the antioxidant potential via HAT process of the three studied compounds is classified in the increasing trend: $\mathbf{C} \mathbf{2}<\mathbf{C} 3 \approx \mathbf{C 1}$. For RAF mechanism, $\mathbf{C} \mathbf{1}$ and $\mathbf{C} 2$ are potent in gas phase while the $\mathbf{C} 3$ is more effective in water.

\subsection{Kinetics}

In order to identify the main existing form of C1-C3 (i.e. neutral, protonated or deprotonated forms) at the physiological condition ( $\mathrm{pH}=7.4), \mathrm{pK}_{\mathrm{a}}$ value needs to be determined. ${ }^{56} \mathrm{The}_{\mathrm{pK}}$ of three aaptamines C1-C3 were calculated at the M05-2X/6-311++G(d,p) level of theory. Similar calculation for aniline at the same level of theory was performed for comparison; the obtained value of $\mathrm{pK}_{\mathrm{a}}$ is 31.1 at $298.15 \mathrm{~K}$ for aniline, consistent with the experimental data, i.e. 30.6 or 28.0, reported in DMSO and in water, respectively. ${ }^{57,58}$ For our aaptamines, the result shows that 
$\mathrm{pK}_{\mathrm{a}}$ of C1-C3 are of 22.8, 23.6 and 22.4, respectively. Therefore, the neutral form of C1-C3 in water is considered in the following calculations.

The kinetics of the possible reactions was studied with the neutral forms of C1-C3 in gas phase and water, for the $\mathrm{OOH}^{\bullet}$ scavenging. The Gibbs free energy of activation $\left(\Delta G^{\ddagger}\right)$ and transition state theory (TST) rate constant $\left(k_{\mathrm{TST}}\right)$ for all reactions were systematically calculated at the M05$2 \mathrm{X} / 6-311++\mathrm{G}(\mathrm{d}, \mathrm{p})$ level of theory. Gibbs free energy of activation and TST rate constants obtained in the gas phase are presented in Table 5. Optimized structures of the transition states (TSs) for FHT and RAF reaction in both phases are presented in the Figures $\mathbf{3}$ and $\mathbf{4}$.

Table 5: Gibbs free energy of activation $\left(\Delta G^{\ddagger}\right.$, in $\left.\mathrm{kcal} \mathrm{mol}^{-1}\right)$ at standard concentration (1M) and TST rate constant $\left(k_{\mathrm{TST}}\right.$, in $\mathrm{cm}^{3}$ molecule $\left.{ }^{-1} \mathrm{~s}^{-1}\right)$ including the Eckart tunneling correction at 298.15 $\mathrm{K}$ calculated in the gas phase for FHT, RAF and SET reactions of C1-C3 towards HOO` radical. Calculations are performed at the M05-2X/6-311++G(d,p) level of theory.

\begin{tabular}{|c|c|c|}
\hline Reaction & 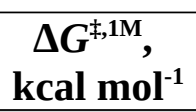 & $\begin{array}{c}k_{\mathrm{TST}}{ }^{298.15 K}, \\
\text { cm }^{3} \text { molecule }^{-1} \mathrm{~s}^{-1}\end{array}$ \\
\hline \multicolumn{3}{|c|}{ FHT } \\
\hline C1@C19H + HOO• & 16.8 & $9.10 \times 10^{-19}$ \\
\hline C2@N14H + HOO• & 19.3 & $2.60 \times 10^{-21}$ \\
\hline C3@C21H + HOO• & 19.8 & $2.30 \times 10^{-19}$ \\
\hline Ascorbic + HOO• & 9.2 & $3.10 \times 10^{-15}$ \\
\hline \multicolumn{3}{|c|}{ RAF } \\
\hline C1@C8 + HOO• & 14.8 & $3.40 \times 10^{-19}$ \\
\hline C2@C2 + HOO• & 14.0 & $3.80 \times 10^{-18}$ \\
\hline C3@C12 + HOO• & 15.6 & $7.60 \times 10^{-21}$ \\
\hline Ascorbic + HOO• & 15.0 & $3.60 \times 10^{-19}$ \\
\hline \multicolumn{3}{|c|}{ SET } \\
\hline $\mathbf{C 1}+\mathrm{HOO} \bullet$ & 420.9 & $4.30 \times 10^{-295}$ \\
\hline $\mathbf{C} 2+\mathrm{HOO} \bullet$ & 378.7 & $3.93 \times 10^{-264}$ \\
\hline $\mathbf{C 3}+\mathrm{HOO} \bullet$ & 401.3 & $1.05 \times 10^{-280}$ \\
\hline
\end{tabular}

For FHT reaction, the compounds $\mathbf{C 1}$ and $\mathbf{C} 3$ display the activation Gibbs free energy of 16.8 and $19.8 \mathrm{kcal} \mathrm{mol}^{-1}$, respectively. Similar rate constants are also obtained for two compounds $\mathbf{C 1}$ and C3 $\left(\sim 10^{-19} \mathrm{~cm}^{3}\right.$ molecule $\left.{ }^{-1} \mathrm{~s}^{-1}\right)$, which is much smaller than the one of a standard antioxidant such as ascorbic acid calculated in the same condition $\left(\sim 10^{-15} \mathrm{~cm}^{3}\right.$ molecule $\left.{ }^{-1} \mathrm{~s}^{-1}\right)$. For the RAF reaction, the lowest activation Gibbs free energy $\Delta G^{\ddagger}\left(14.0 \mathrm{kcal} \mathrm{mol}^{-1}\right)$ and the highest rate constant $\left(3.80 \times 10^{-18} \mathrm{~cm}^{3}\right.$ molecule $\left.\mathrm{e}^{-1} \mathrm{~s}^{-1}\right)$ are obtained for $\mathbf{C} 2$ at C2 position, indicate the most favorable reaction. At the second place, the $\mathbf{C} \mathbf{1}$ is found with similar activation Gibbs free energy

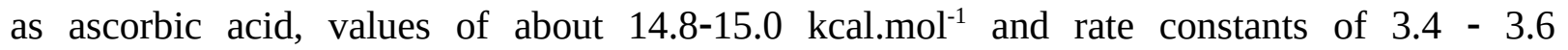
$\times 10^{-19} \mathrm{~cm}^{3}$ molecule ${ }^{-1} \mathrm{~s}^{-1}$. In the contrary, the SET reaction is found with very high activation energy of about $400 \mathrm{kcal}_{\mathrm{mol}}^{-1}$ and near-zero rate constants. 
For the reactions in water, kinetics data including the Gibbs free energy of activation $\Delta G^{\ddagger}$, the diffusion rate constants $k_{\mathrm{D}}$, thermal rate constant $k_{\mathrm{T}}$, Eckart-tunneling-corrected rate constants $k_{\text {eck, }}$ diffusion-corrected rate constants $\mathrm{k}_{\mathrm{app}}$, and the branching ratio $\Gamma(\%)$ for each reaction FHT, RAF and SET are resumed in Table 6.

Table 6: Gibbs free energy of activation $\left(\Delta G^{\ddagger}, \mathrm{kcal} \mathrm{mol}^{-1}\right)$, diffusion rate constant $\left(k_{\mathrm{D}}, \mathrm{M}^{-1} \mathrm{~s}^{-1}\right)$, TST thermal rate constant $\left(k_{\mathrm{T}}, \mathrm{M}^{-1} \mathrm{~s}^{-1}\right)$, Eckart-tunneling-corrected rate constants $\left(k_{\text {eck }}, \mathrm{M}^{-1} \mathrm{~s}^{-1}\right)$, diffusion-corrected apparent rate constants $\left(k_{\mathrm{app}}, \mathrm{M}^{-1} \mathrm{~s}^{-1}\right)$ and branching ratio $\Gamma(\%)$ calculated at $298 \mathrm{~K}$ for the FHT, RAF and SET mechanism with HOO• radical in water.

\begin{tabular}{|c|c|c|c|c|c|c|}
\hline Reaction path & $\begin{array}{c}\Delta G^{\ddagger, 1 \mathrm{M}}, \\
\mathrm{kcal}^{\mathrm{mol}} \mathrm{mol}^{-1}\end{array}$ & $k_{\mathrm{D}}, \mathbf{M}^{-1} \mathrm{~s}^{-1}$ & $k_{\mathrm{T}}, \mathbf{M}^{-1} \mathbf{s}^{-1}$ & $k_{\text {eck }}, \mathbf{M}^{-1} \mathbf{s}^{-1}$ & $k_{\mathrm{app}}, \mathbf{M}^{-1} \mathbf{s}^{-1}$ & $\Gamma, \%$ \\
\hline \multicolumn{7}{|c|}{ FHT } \\
\hline C1@C19H + HOO• & -0.87 & $1.40 \times 10^{9}$ & $7.17 \times 10^{6}$ & $3.22 \times 10^{-15}$ & $7.13 \times 10^{6}$ & 96 \\
\hline C2@N14H + HOO• & 22.2 & $2.60 \times 10^{9}$ & $3.60 \times 10^{-4}$ & $6.10 \times 10^{0}$ & $6.10 \times 10^{0}$ & 0 \\
\hline C3@C21H + HOO• & 5.17 & $1.27 \times 10^{9}$ & $3.84 \times 10^{3}$ & $3.22 \times 10^{-16}$ & $3.84 \times 10^{3}$ & 1 \\
\hline \multicolumn{7}{|c|}{ RAF } \\
\hline C1@C8 + HOO• & 7.2 & $2.10 \times 10^{9}$ & $3.00 \times 10^{7}$ & $2.80 \times 10^{5}$ & $2.80 \times 10^{5}$ & 4 \\
\hline C2@C2 + HOO• & 5.6 & $2.20 \times 10^{9}$ & $4.20 \times 10^{8}$ & $1.40 \times 10^{5}$ & $1.40 \times 10^{5}$ & 100 \\
\hline C3@C12 + HOO• & 7.5 & $2.00 \times 10^{9}$ & $1.90 \times 10^{7}$ & $2.90 \times 10^{5}$ & $2.90 \times 10^{5}$ & 99 \\
\hline \multicolumn{7}{|c|}{ SET } \\
\hline $\mathbf{C 1}+\mathrm{HOO} \bullet$ & 47.10 & $8.22 \times 10^{9}$ & $4.56 \times 10^{-21}$ & - & $4.56 \times 10^{-21}$ & 0 \\
\hline $\mathbf{C 2}+\mathrm{HOO} \bullet$ & 45.91 & $8.26 \times 10^{9}$ & $3.35 \times 10^{-20}$ & - & $3.35 \times 10^{-20}$ & 0 \\
\hline $\mathbf{C 3}+\mathrm{HOO} \bullet$ & 53.19 & $8.47 \times 10^{9}$ & $1.55 \times 10^{-25}$ & - & $1.55 \times 10^{-25}$ & 0 \\
\hline
\end{tabular}

For FHT reaction at the $\mathrm{C} 19 \mathrm{H}$ position of $\mathbf{C 1}$, it happens to be a barrierless reaction, with negative Gibbs free energy of activation $\left(-0.87 \mathrm{kcal} \mathrm{mol}^{-1}\right)$. Moreover, the rate constant obtained at this position is of $7.13 \times 10^{6} \mathrm{M}^{-1} \mathrm{~s}^{-1}$. On the contrary, the FHT reaction of C3 requires 5.17 $\mathrm{kcal} \mathrm{mol}^{-1}$ of Gibbs free energy of activation and appears with a rate constant of only $3.84 \times 10^{3}$ $\mathrm{M}^{-1} \mathrm{~s}^{-1}$. Moreover, FHT reaction is not favored for the $\mathbf{C} 2$ with very high reaction barrier (22.2 $\left.\mathrm{kcal} \mathrm{mol}^{-1}\right)$ and even lower apparent rate constant $\left(6.10 \mathrm{M}^{-1} \mathrm{~s}^{-1}\right)$. For RAF reaction, the reaction barriers $\left(\Delta G^{\ddagger}\right)$ are found to be 5.6, 7.2 and $7.5 \mathrm{kcal} \mathrm{mol}^{-1}$ for $\mathbf{C 1}, \mathbf{C} 2, \mathbf{C} 3$, respectively. As can be seen in the Table 6 , the diffusion rate constants $k_{\mathrm{D}}$ of RAF are of about $10^{9} \mathrm{M}^{-1} \mathrm{~s}^{-1}$, while the thermal rate constants are much smaller $\left(\sim 10^{5} \mathrm{M}^{-1} \mathrm{~s}^{-1}\right)$. The RAF apparent rate is observed with C2 at the C2 position with $k_{\text {app }}=1.40 \times 10^{5} \mathrm{M}^{-1} \mathrm{~s}^{-1}$ while a double $k_{\text {app }}$ values $\left(2.8-2.9 \times 10^{5} \mathrm{M}^{-1}\right.$ $\mathrm{s}^{-1}$ ) are obtained for $\mathbf{C 1}$ and C3. These results show higher reaction rate of C2 and C3 via RAF than via FHT mechanism. Similar as in the gas phase, the SET reaction of all three compounds requires very high activation Gibbs free energy (45-53 $\mathrm{kcal} \mathrm{mol}^{-1}$ ) and occurred at extremely small rate $\left(10^{-25}-10^{-20} \mathrm{M}^{-1} \mathrm{~s}^{-1}\right)$. Overall, we observed a competition of the FHT and RAF reaction for the $\mathrm{HOO}$ • scavenging depending on the chemical nature of the substituents to the aaptamine. 
For C1, the FHT reaction is dominant with branching ratio being $96 \%$, while the $\mathrm{HOO}$ scavenging via RAF is more favored with $\mathbf{C} 2$ and $\mathbf{C} 3$ with $\Gamma$ values being 100 and $99 \%$, respectively.

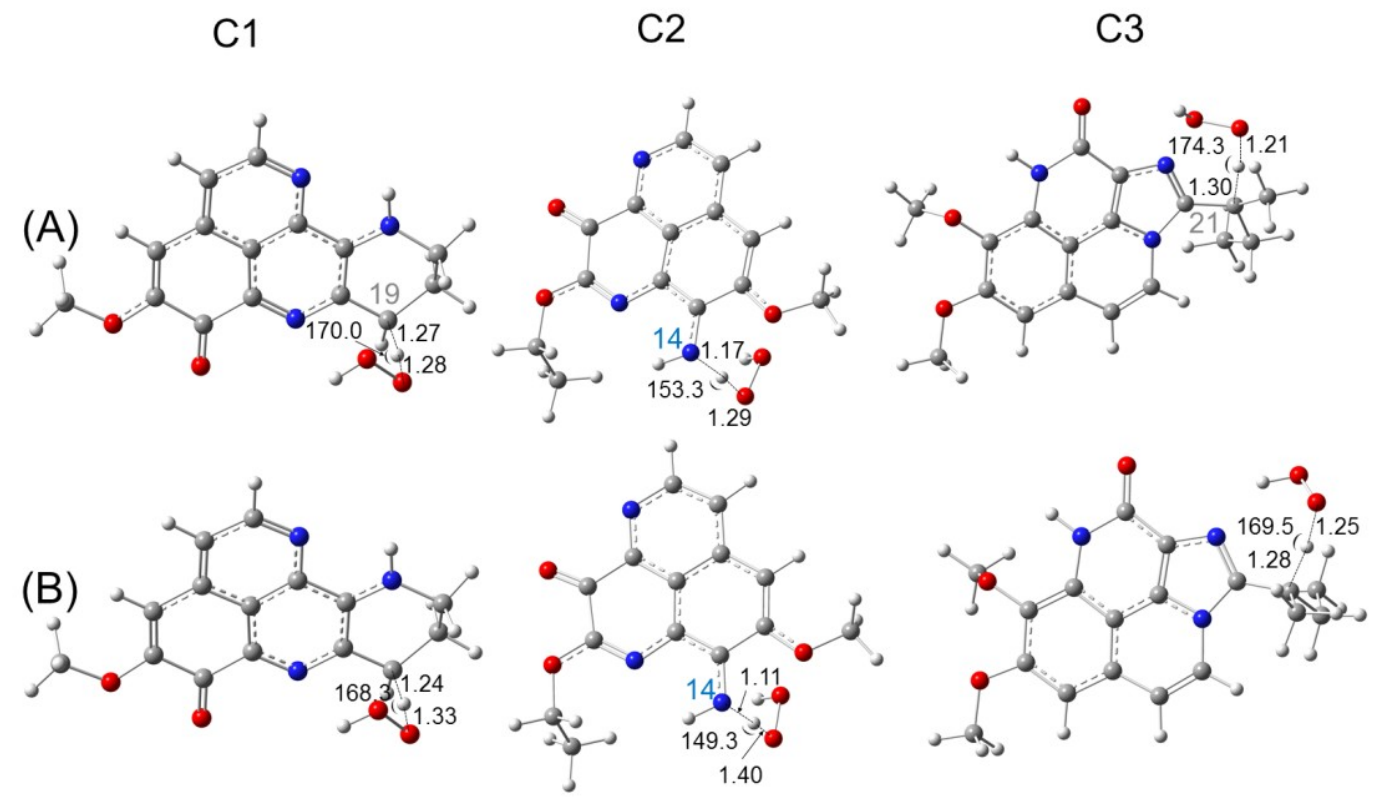

Figure 3: Optimized structures of the transition state for FHT reaction of C1, C2, C3 with HOO radical in the gas phase (A) and in water $(\mathbf{B})$ at the easiest $\mathrm{H}$ donating positions. Calculations are performed at the M05-2X/6-311++G(d,p) level of theory.

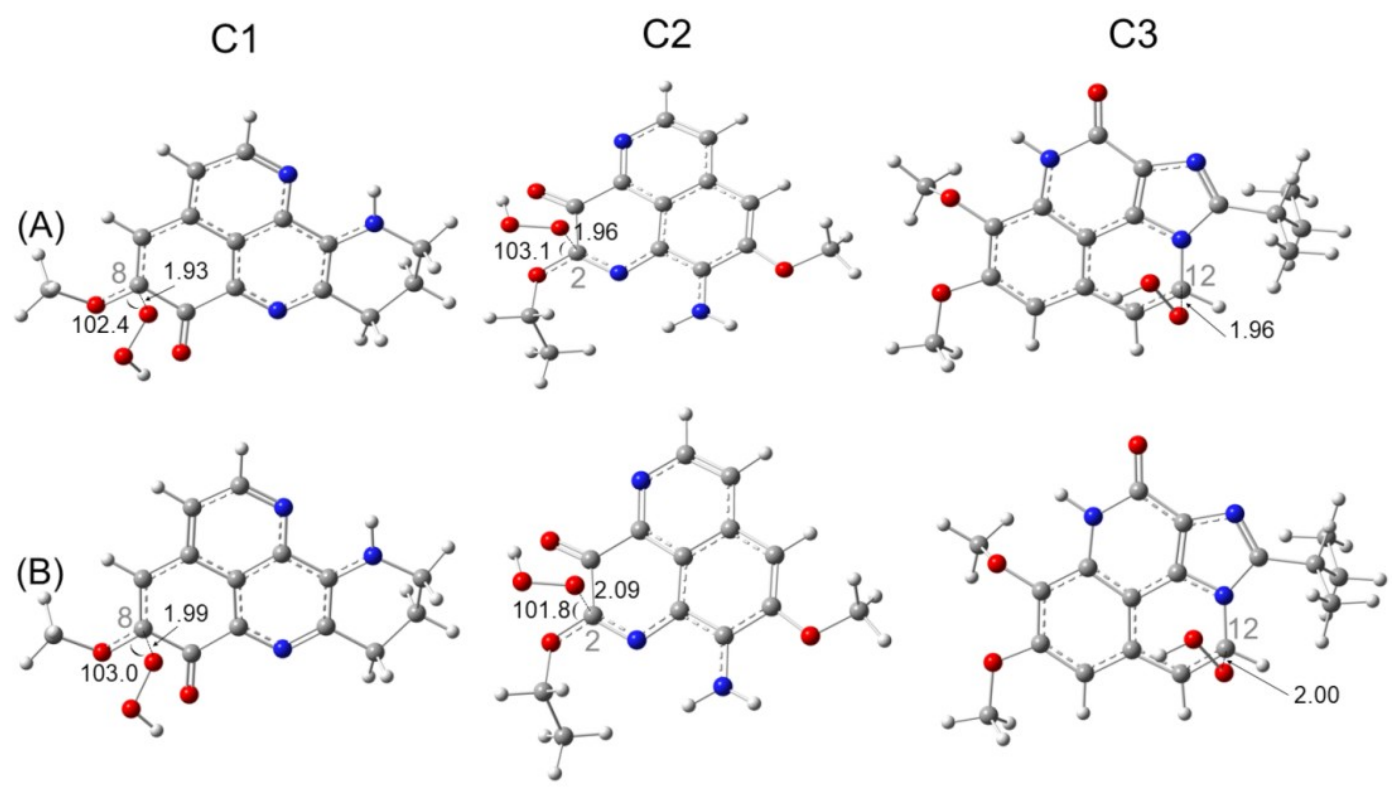


Figure 4: Optimized structures of the transition state for RAF reaction of $\mathbf{C 1}, \mathbf{C 2}, \mathbf{C} 3$ with $\mathrm{HOO}^{\bullet}$ radical in the gas phase $(\mathbf{A})$ and in water $(\mathbf{B})$ at the most spontaneous addition positions.

Calculations are performed at the M05-2X/6-311++G(d,p) level of theory.

\subsection{Formal H transfer - HAT or PCET?}

In order to answer the question how and whether or not the electron and proton are transferred in many important energy conversion processes in chemistry and biology, ${ }^{59}$ the chemical nature of the FHT process for the aaptamine derivatives with $\mathrm{HOO}^{\bullet}$ radical is analyzed in this section. Identifying the HAT and PCET mechanisms is a difficult mission because the same reactants and the same products are recognized between these two mechanisms, although the reaction pathways are totally different. Analyses of singly occupied molecular orbital (SOMO) distribution (Figure 5) and of electronic properties such as NPA charges, atomic spin densities (ASD), natural electron configuration (NEC) calculated at the transition states (TSs) (Table 7) as well as NBO analyses (Table 8) allow addressing this problem.
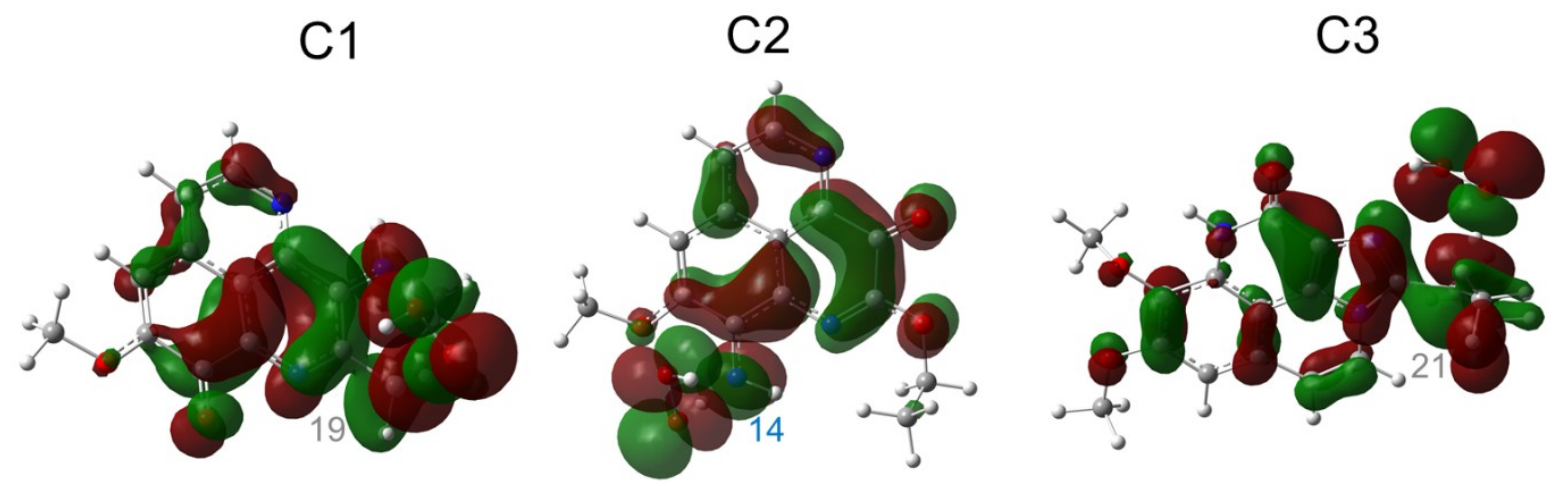

Figure 5: SOMO distributions of the transition states (TSs) for FHT reactions at the easiest H donating positions.

Figure 5 represents first the SOMO distributions at the TSs for FHT reactions of three aaptamine compounds with $\mathrm{HOO}^{\circ}$ radical in the gas phase. It is reported that SOMO of HAT TSs is distributed with significant densities in orbitals along the $\mathrm{H}$-shifting vector between the donor and acceptor, while the one of PCET TSs is orthogonal to the transition vector. ${ }^{60}$ As can be seen in Figure 5, the $2 p$ orbitals of the acceptor (i.e. $\mathrm{O} 34$ and $\mathrm{O} 44$ atom of the $\mathrm{HOO}^{\bullet}$ radical) and the one of the donor (i.e. C atoms or N14 atom) are interacted and distributed along the H-shifting vector whereas the $\pi$-electrons on the $\mathrm{HOO}^{*}$ radical and the ones on the aromatic rings of aaptamines are tunneled together. This observation consists in the first signal for a $\mathrm{H}$ atom transfer (HAT) nature. 
To shed more light into changes of electron densities at the transition states of FHT processes, we investigated natural bond orbitals (NBO) analysis (Table 7). As a result, for the FHT reaction between $\mathbf{C 1}$ and $\mathrm{HOO}^{•}$ at the $\mathrm{C} 19 \mathrm{H}$ position (C1@C19H + HOO'), the electron densities are transferred from the first $\sigma$-bonding of $\mathrm{C} 19-\mathrm{H}$ bond, $\sigma(1) \mathrm{C} 19-\mathrm{H}$, to the first $\sigma$-antibonding of O34-O35 bond, $\sigma^{*}(1)$ O34-O35, with a stabilization energy [E(2)] of $7.7 \mathrm{kcal} \mathrm{mol}^{-1}$. Conversely, the electron densities are also transferred from the lone pairs of electron on $\mathrm{O} 34$ atom of HOO radical, LP(1) O34, LP(2) O34 and LP(3) O34, to the $\sigma^{*}(1) \mathrm{C} 19-\mathrm{H}$ with the E(2) values being 324.3, 27.2 and $255.8 \mathrm{kcal} \mathrm{mol}^{-1}$, respectively. For the reaction C2@N14H + HOO', only the electron transfer from $\sigma$-antibonding of N14-H bond, $\sigma^{*}(1) \mathrm{N} 14-\mathrm{H}$, to the one of O34O35 bond, $\sigma^{*}(1)$ O34-O35, is observed with a small $\mathrm{E}(2)$ value of $5.5 \mathrm{kcal} \mathrm{mol}^{-1}$. A similar observation is found the reaction $\mathbf{C} 3 @ \mathrm{C} 21 \mathrm{H}+\mathrm{HOO}^{*}$. In fact, the electron densities are essentially changed from $\sigma^{*}(1) \mathrm{C} 21-\mathrm{H}$ to $\sigma^{*}(1)$ O34-O35 with the stabilization energy E(2) being $1293.7 \mathrm{kcal} \mathrm{mol}^{-1}$. In the reverse trend, the electrons from the lone pair on $\mathrm{O} 44$ and $\mathrm{O} 45$ atoms, $\mathrm{LP}(1) \mathrm{O} 44$ and $\mathrm{LP}(1) \mathrm{O} 45$, of the HOO${ }^{*}$ radical to the first $\sigma$-antibonding on C21-C24 bond, $\sigma^{*}(1) \mathrm{C} 21-\mathrm{C} 24$, with the $\mathrm{E}(2)$ values being 5.6 and $77.5 \mathrm{kcal} \mathrm{mol}^{-1}$, respectively.

Table 7: NBO analysis investigated at the transition states (TSs) of FHT reactions between C1-C3 compounds and $\mathrm{HOO} \bullet$ radical

\begin{tabular}{|l|l|l|l|}
\hline Reactions & Donor NBO (i) & Acceptor NBO (j) & E(2), kcal mol \\
\hline \multirow{5}{*}{ C1@C19H + HOO } & $\sigma(1)$ C19-H & $\sigma^{*}(1)$ O34-O35 & 7.7 \\
\cline { 2 - 4 } & $\pi(1)$ O34-O35 & $\sigma^{*}(1)$ C19-H & 44.8 \\
\cline { 2 - 4 } & LP(2) O34 & $\sigma^{*}(1)$ C19-H & 27.2 \\
\cline { 2 - 4 } & LP(3) O34 & $\sigma^{*}(1)$ C19-H & 255.8 \\
\cline { 2 - 4 } & LP(1) O35 & $\sigma^{*}(1)$ C19-H & 324.3 \\
\hline C2@N14H + HOO• & $\sigma^{*}(1)$ N14-H & $\sigma^{*}(1)$ O34-O35 & 5.5 \\
\hline C3@C21H + HOO• & $\sigma^{*}(1)$ C21-H & $\sigma^{*}(1)$ O44-O45 & 1293.7 \\
\cline { 2 - 4 } & LP(1) O45 & $\sigma^{*}(1)$ C21-C24 & 77.5 \\
\cline { 2 - 4 } & LP(1) O44 & $\sigma^{*}(1)$ C21-C24 & 5.6 \\
\hline
\end{tabular}

Table 8: NPA charges, atomic spin densities (ASD), natural electron configuration (NEC) calculated at the transition states (TSs) for shifting-H, donor and acceptor of $\mathbf{C 1}-\mathbf{C} 3$.

\begin{tabular}{|c|c|c|l|}
\hline Atom & NPA charges & ASD & \multicolumn{1}{|c|}{ NEC } \\
\hline C1@C19H + HOO \\
\hline C19 & -0.3535 & 0.41185 & $2 \mathrm{~S}^{1.02} 2 \mathrm{p}^{3.31}$ \\
\hline $\mathrm{H}$ & 0.3255 & -0.03654 & $1 \mathrm{~S}^{0.67}$ \\
\hline O34 & -0.3245 & 0.42642 & $2 \mathrm{~S}^{1.81} 2 \mathrm{p}^{4.49}$ \\
\hline C2@N14H + HOO \\
\hline N14 & -0.6605 & 0.26019 & $2 \mathrm{~S}^{1.39} 2 \mathrm{p}^{4.25}$ \\
\hline $\mathrm{H}$ & 0.4294 & -0.01012 & $1 \mathrm{~S}^{0.61}$ \\
\hline O34 & -0.3943 & 0.32787 & $2 \mathrm{~S}^{1.82} 2 \mathrm{p}^{4.56}$ \\
\hline
\end{tabular}




\begin{tabular}{|c|c|c|l|}
\hline \multicolumn{4}{|l|}{ C3@C21H + HOO } \\
\hline $\mathrm{C} 21$ & -0.1832 & 0.46482 & $2 \mathrm{~S}^{0.96} 2 \mathrm{p}^{3.20}$ \\
\hline $\mathrm{H}$ & 0.3494 & -0.05014 & $1 \mathrm{~S}^{0.64}$ \\
\hline $\mathrm{O} 44$ & -0.3245 & 0.41883 & $2 \mathrm{~S}^{1.80} 2 \mathrm{p}^{4.51}$ \\
\hline
\end{tabular}

Furthermore, natural electron configuration (NEC) of the TSs in Table 8 shows that the mitigated-H species have $1 \mathrm{~S}$ occupancy $1 \mathrm{~S}^{0.61-0.67}$ which likely corresponds to one $\mathrm{H}$ atom with configuration $1 \mathrm{~S}^{1.0}$. In addition, the ASD values of the $\mathrm{H}$ species at the transition state are slightly varying from -0.05014 to -0.01012 . This result is in good agreement with the one observed for HAT reaction of $\alpha$-mangostin with HOO ${ }^{*}$ radical. ${ }^{60}$ Moreover, the NEC of carbon centereddonors in $\mathbf{C 1}$ and $\mathbf{C} 3$ shows the configurations $2 \mathrm{~S}^{0.96-1.02} 2 \mathrm{p}^{3.20-3.31}$ likely $2 \mathrm{~s} 2 \mathrm{p}^{3}$, while the one of nitrogen-based donor in $\mathbf{C} 2$ has the configuration $2 \mathrm{~S}^{1.39} 2 \mathrm{p}^{4.25}$ likely $2 \mathrm{~s} 2 \mathrm{p}^{4}$. In the same time, the $\mathrm{H}$-acceptors (i.e. O34 and $\mathrm{O} 44$ atoms) have the electron configurations $2 \mathrm{~S}^{1.80-1.82} 2 \mathrm{p}^{4.49-4.56}$ which are similar with the $2 \mathrm{~s}^{2} 2 \mathrm{p}^{4}$. In addition, the spin densities are all distributed at the donors $(0.26019-0.46482)$ and at the acceptors $(0.32787-0.42642)$. These observations support the conclusion that the shifted-H has an atom character rather than a proton one. Thus, the FHT processes of all three aaptamines have the chemical nature of HAT mechanism.

\subsection{Indirect antioxidant potential via copper ions chelating properties}

Besides ferric ion [i.e. Fe(III)], the cupric ion $\mathrm{Cu}(\mathrm{II})$ consists in one of the most abundant cations available in most organisms and in human body.$^{18}$ Although they are themselves not harmful species, their reduction can lead to the formation of very reactive hydroxyl $\mathrm{HO}^{\bullet}$ radical via the Haber-Weiss cycle. ${ }^{61}$ Regarding to $\mathrm{Cu}(\mathrm{II})$ ion, its complexation with the potential antioxidant compounds could sometime prevent the reduction process that forms $\mathrm{Cu}(\mathrm{I})$ ion and $\mathrm{HO}^{\bullet}$ radical. The fact was that, several potential antioxidants show good copper ions chelating abilities were reported with aminoguanidine,${ }^{62}$ pyridoxamine, ${ }^{63}$ lipoic and dihydrolipoic acids,${ }^{64}$ purine,${ }^{18}$ citric acid ${ }^{65}$ D-penicillamine, ${ }^{66}$ 2-hydroxymelatonin and 4-hydroxymelatonin. ${ }^{16}$ In this study, the $\mathrm{Cu}(\mathrm{II})$ complexes formed by the chelating process of the three aaptamines at different possible chelation sites in water phase are evaluated in Figure 6, while the similar complexes with $\mathrm{Cu}(\mathrm{I})$ ion are also presented in Figure 7. Standard enthalpies $\left(\Delta H^{0}\right)$ and Gibbs free energies $\left(\Delta G^{0}\right)$ of the complexation processes ( $\mathrm{R} 8$ and R9) are also calculated to evaluate the stability of the obtained complexes. Only bidentate complexes with the hydrated copper ions,i.e. $\left[\mathrm{Cu}(\mathrm{I}) \cdot 4 \mathrm{H}_{2} \mathrm{O}\right]^{+}$ and $\left[\mathrm{Cu}(\mathrm{II}) \cdot 4 \mathrm{H}_{2} \mathrm{O}\right]^{2+}$ are considered because they are more stable than the monodentate ones as showed by several studies in literature mentioned above. 

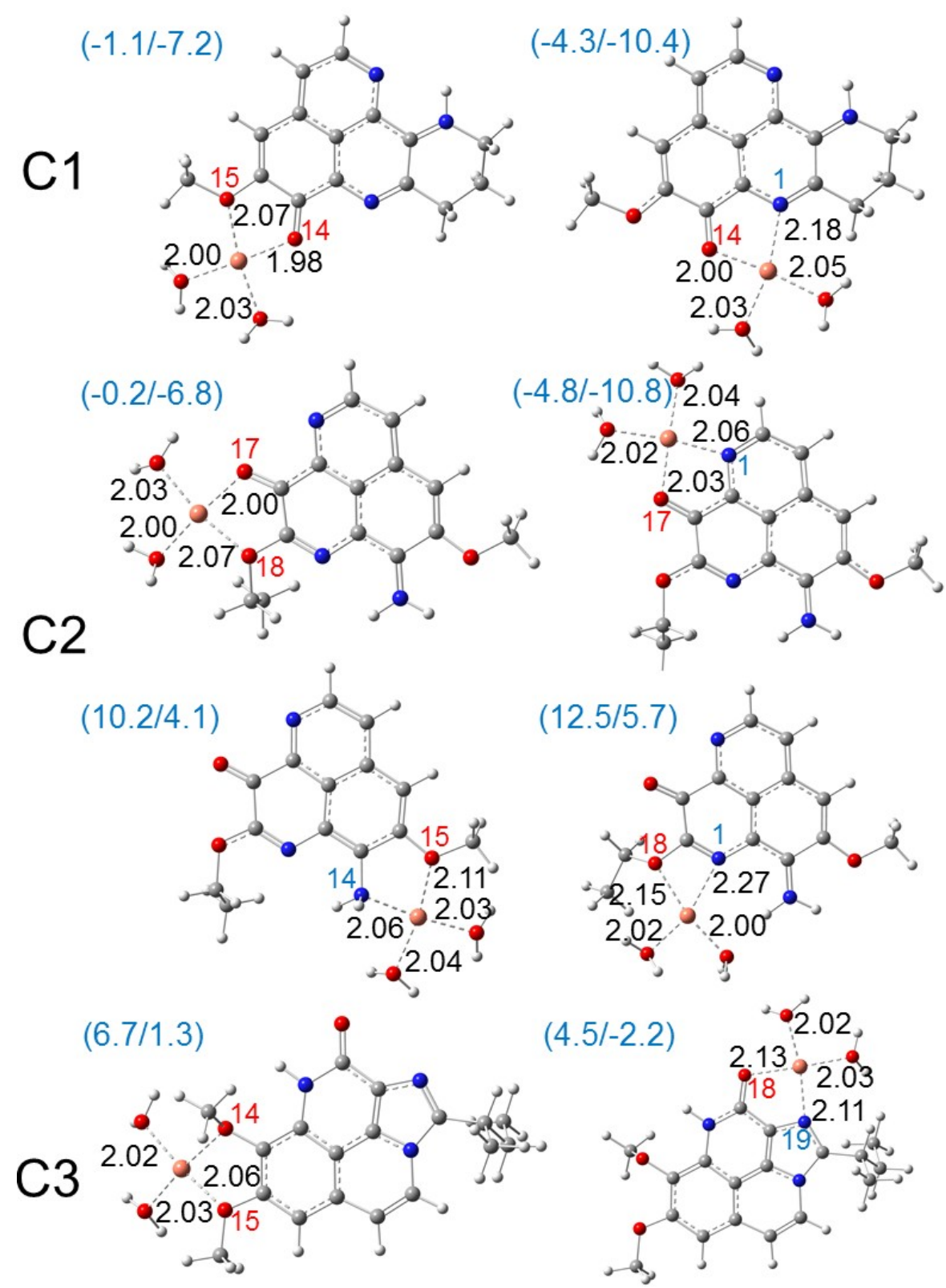

Figure 6: Optimized structures of the bidentate $\mathrm{Cu}(\mathrm{II})$ complexes of three aaptamines $\mathbf{C 1}-\mathbf{C 3}$ in water phase calculated at the M05-2X functional with the basis set LanL2DZ for Cu and the 6$311++G(d, p)$ for other elements. The standard enthalpies $\left(\Delta H^{0}\right)$ and Gibbs free energies $\left(\Delta G^{0}\right)$ of the complexation reactions in $\mathrm{kcal} \mathrm{mol}^{-1}$ are given in the parentheses. Coordinated oxygen and nitrogen atoms are numbered in red and blue, respectively. Bond distances (in angstroms) are noted in black. 

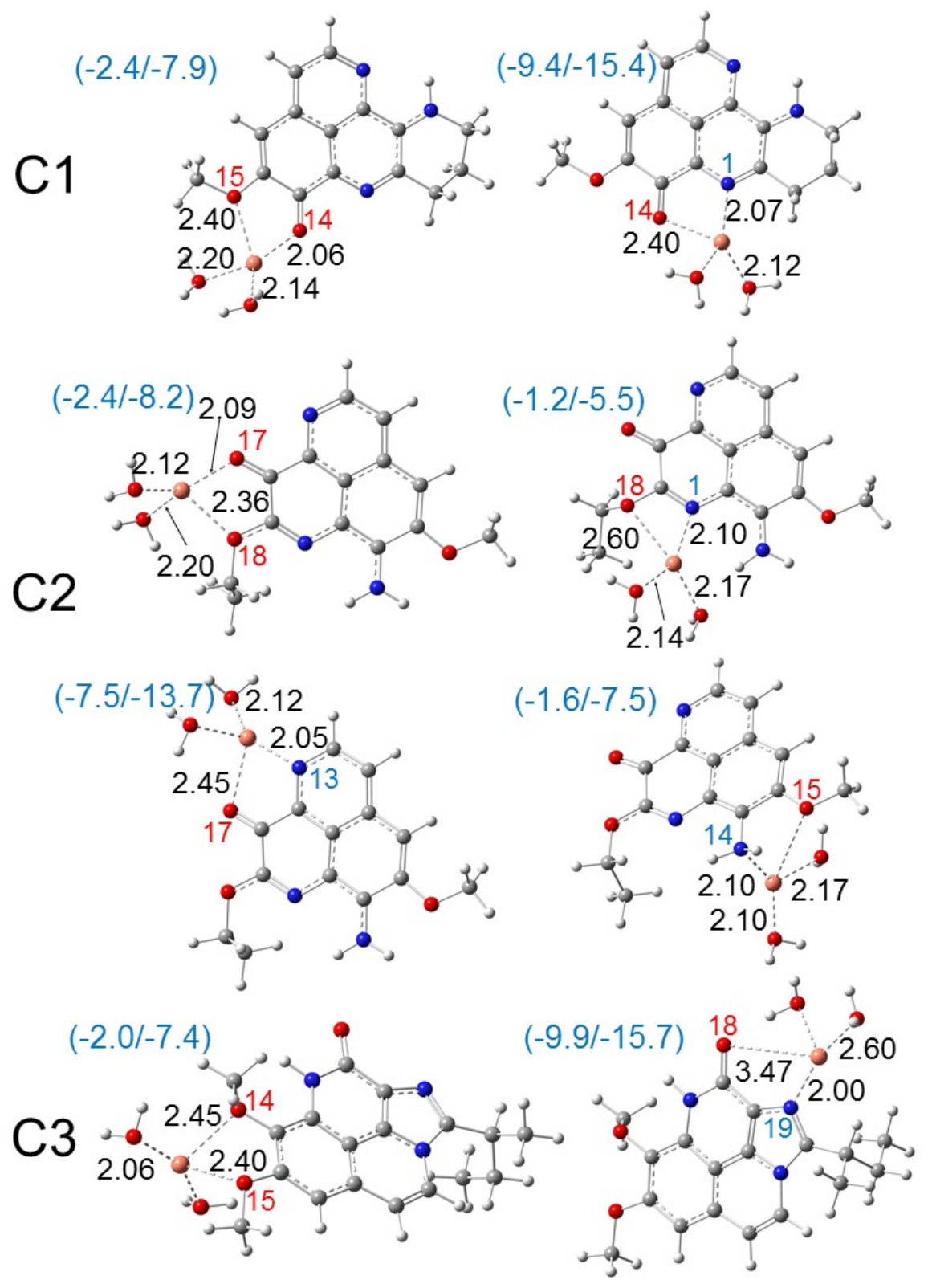

Figure 7: Optimized structures of the bidentate copper (I) complexes of three aaptamines $\mathbf{C 1}$ C3 in water phase calculated at the M05-2X functional with the basis set LanL2DZ for Cu and the 6-311++G(d,p) for other elements. The standard enthalpies $\left(\Delta H^{0}\right)$ and Gibbs free energies $\left(\Delta G^{0}\right)$ of the complexation reactions in $\mathrm{kcal} \mathrm{mol}^{-1}$ are given in the parentheses. Coordinated oxygen and nitrogen atoms are numbered in red and blue, respectively. Bond distances (in angstroms) are noted in black.

As can be seen in Figure 6, all the three aaptamine compounds show spontaneous and favorable $\mathrm{Cu}$ (II) ion chelating activities with negative $\Delta H^{0}$ and $\Delta G^{0}$ values. Indeed, the most favorable 
chelating site for $\mathbf{C} \mathbf{1}$ is found at O14/N1 with $\Delta H^{0} / \Delta G^{0}$ being $-4.3 /-10.4 \mathrm{kcal} \mathrm{mol}^{-1}$. Similarly, the most favorable site for $\mathbf{C} 2$ is at O17/N1 with $\Delta H^{0} / \Delta G^{0}$ being $-4.8 /-10.8 \mathrm{kcal} \mathrm{mol}^{-1}$, and for $\mathbf{C} 3$ being at $\mathrm{O} 18 / \mathrm{N} 19\left(\Delta H^{0} / \Delta G^{0}\right.$ being 4.5/-2.2 $\left.\mathrm{kcal} \mathrm{mol}^{-1}\right)$. Thus, the $\mathrm{Cu}(\mathrm{II})$ ion chelating activities of three studied compounds can be ranged in the increasing trend: $\mathbf{C 3}<\mathbf{C 1}<\mathbf{C 2}$. The $\mathrm{Cu}$ (II) chelation of the studied aaptamines are better than the one of aminoguanidine $\left(\Delta G^{0}, 13.8 \mathrm{kcal}\right.$ $\left.\mathrm{mol}^{-1}\right),{ }^{62}$ 2-hydroxymelatonin and 4-hydroxymelatonin $\left(\Delta G^{0},-5.59\right.$ and $0.63 \mathrm{kcal} \mathrm{mol}^{-1}$, respectively $)^{16}$ and D-penicillamine $\left(\Delta G^{0}, 0.3 \mathrm{kcal} \mathrm{mol}^{-1}\right) \cdot{ }^{66}$

Furthermore, it is noteworthy that the $\mathrm{Cu}(\mathrm{I})$ complexation is more favorable than the one of $\mathrm{Cu}(\mathrm{II})$ ion for all three compounds at the same chelation site. For example, the $\Delta H^{0}$ and $\Delta G^{0}$ values of the complexation process at the $014 / \mathrm{N} 1$ site of $\mathbf{C 1}$ are -9.4 and $-15.4 \mathrm{kcal} \mathrm{mol}^{-1}$, respectively. For $\mathbf{C} 2$ at the $\mathrm{O} 17 / \mathrm{N} 13$ site, the formed $\mathrm{Cu}(\mathrm{I})$ complex is also stable with $\Delta H^{0} / \Delta G^{0}$ being -7.5/-13.7 kcal mol ${ }^{-1}$, while the $\Delta H^{0} / \Delta G^{0}$ values for $\mathbf{C} 3$ at the O18/N19 chelating site are equal to $-9.9 /-15.7 \mathrm{kcal} \mathrm{mol}^{-1}$. It is noted that the $\mathrm{Cu}(\mathrm{I})$ chelating activities are in the increasing order: $\mathbf{C} \mathbf{2}<\mathbf{C 1}<\mathbf{C} 3$, which is in the reverse order in comparison with the $\mathrm{Cu}(\mathrm{II})$ ones.

Thus, all three aaptamine derivatives present the spontaneous and favorable formation of the complexes with both $\mathrm{Cu}(\mathrm{II})$ and $\mathrm{Cu}(\mathrm{I})$ hydrated ions in water phase. This reduces the availability of these ions to participate in the Haber-Weiss cycle in forming the hydroxyl radical.

\section{7. $\mathrm{UV}$ radiation absorption properties}

The vertical excitation of the molecules C1-C3 is studied with TD-DFT using different functionals such as B3LYP, B98, M06, PBE0, CAM-B3LYP and M05-2X as previously recommended for accuracy. ${ }^{52}$ In order to compare with experimental data reported in $\mathrm{MeOH},{ }^{4}$ all calculation is performed in $\mathrm{MeOH}$ using the implicit model IEF-PCM. The lowest absorption wavelength of each compound calculated by six above-mentioned functionals is presented in the Table 9 in comparison with the measured data.

Table 9: Lowest absorption wavelength (nm) of C1-C3 calculated by TD-DFT with different methods of various \% HF in exchange correlation.

\begin{tabular}{|c|c|c|c|c|}
\hline \multirow{2}{*}{ Method } & \multirow{2}{*}{ \%HF } & \multicolumn{3}{|c|}{ Absorption / nm } \\
\cline { 3 - 5 } & & C1 & C2 & C3 \\
\hline B3LYP & 20 & 471 & 482 & 332 \\
\hline B98 & 22 & 465 & 476 & 327 \\
\hline M06 & 27 & 461 & 472 & 329 \\
\hline PBE0 & 25 & 459 & 470 & 322 \\
\hline CAM-B3LYP $^{*}$ & $19 / 65$ & 427 & 439 & 298 \\
\hline M05-2X & 56 & 423 & 435 & 292 \\
\hline Exp. (ref. $^{4}$ ) & & 398 & 402 & 350 \\
\hline
\end{tabular}

* $19 \% \mathrm{HF}$ at short-range and $65 \% \mathrm{HF}$ at long-range 
As can be seen in Table 9, among the different methods, a fairly consistent result in comparison with the experimental data is obtained with CAM-B3LYP and M05-2X functional. For example, the lowest absorption of $\mathbf{C 1}$ calculated in $\mathrm{MeOH}$ by $\mathrm{M} 05-2 \mathrm{X}$ is found at $423 \mathrm{~nm}$ while the experimental value was reported at $398 \mathrm{~nm}$ in the same solvent (25 nm deviation). Similar deviation of about $30 \mathrm{~nm}$ was obtained for C2. However, a much higher deviation is observed with C3, for which a shorter wavelength of $292 \mathrm{~nm}$ is absorbed vs. $350 \mathrm{~nm}$ in measurement. The other methods, which comprise a portion of 20-30 \% HF in exchange correlation, give much less-comparative absorption. For example, the B3LYP functional (20 \% HF) provides much higher absorption wavelengths, i.e. 471, 482 and $332 \mathrm{~nm}$ for C1-C3, respectively. As discussed in the literature, the main drawback of TD-DFT consists of the underestimation of the vertical excited energy, for which a significant error up to $0.4 \mathrm{eV}$ can be found. ${ }^{67}$ However, for comparative purpose, the TD-DFT results in general can still provide a benefit when it treats with the same kind of molecules.

The vertical excited energy of some lowest excitations calculated by TD/M05-2X/6-311+ $+\mathrm{G}(\mathrm{d}, \mathrm{p})$ as well as the oscillator strength and the nature of the corresponding electronic transition are presented in Table 10. Vertical excitations of C1, C2, and C3 are found at 2.93, 2.87 and $4.24 \mathrm{eV}$, respectively. In all cases, we observed mainly the contribution of the HOMO to LUMO transition for the lowest lying excitation of C1-C3. This contribution varies from $96 \%$ for C1, $97 \%$ for $\mathbf{C} 2$ and $86 \%$ for C3. As predicted in the electronic properties part, the HOMO and LUMO of three compounds involved mostly the rings of aaptamine derivatives, then all the lowest absorption is mainly characterized as $\pi-\pi *$ transition.

Finally, the Figure 8 displayed the energy gap and energy level of the frontier molecular orbitals that participated to the lowest electronic transition of the C1-C3. One can easily notice that: (i) there is a much lower gap (4.9 eV) for $\mathbf{C 1}$ and $\mathbf{C} 2$ in comparison with $6.5 \mathrm{eV}$ gap in case of $\mathbf{C}$, and (ii) possessing the same energy level for HOMO, the energy level of LUMO of C1 and C2 is much lower than that of $\mathbf{C} 3$. All results indicate that the $\mathbf{C} \mathbf{1}$ and $\mathbf{C} 2$ can be more easily excited than C3. This agrees with the TD-DFT results, that the $\mathbf{C 1}$ and $\mathbf{C 2}$ absorbed the deep blue and UVA radiation (423/345 and 435/328 nm) while the C3 is effective UVB (292 nm) absorption agent. The results suggest the use of aaptamines $\mathbf{C 1 - C 3}$ as photo-protective agents. 
Table 10. Vertical excited energies (eV), absorption wavelength (nm), oscillator strength $f$ and the corresponding electronic transition of some lowest excited states of C1-C3 calculated by TDDFT at the M05-2X/6-311++G(d,p) level in MeOH.

\begin{tabular}{|c|c|c|c|c|c|c|}
\hline Cp & ES & E/eV & $\mathrm{A} / \mathrm{nm}$ & $f$ & Transition & $\%$ \\
\hline \multirow[t]{5}{*}{$\mathrm{C1}$} & $\mathrm{S}_{1}$ & 2.93 & 423 & 0.3553 & $\mathrm{H} \rightarrow \mathrm{L}$ & 96 \\
\hline & $\mathrm{S}_{3}$ & 3.60 & 345 & 0.1614 & $\mathrm{H}-1 \rightarrow \mathrm{L}$ & 91 \\
\hline & $\mathrm{S}_{7}$ & 4.84 & 257 & 0.4625 & $\begin{array}{l}\mathrm{H}-2 \rightarrow \mathrm{L} \\
\mathrm{H} \rightarrow \mathrm{L}+1\end{array}$ & $\begin{array}{l}47 \\
43\end{array}$ \\
\hline & $\mathrm{S}_{8}$ & 5.33 & 233 & 0.1603 & $\mathrm{H} \rightarrow \mathrm{L}+2$ & 92 \\
\hline & & 5.72 & 212 & 0.0277 & $\begin{array}{l}\mathrm{H}-1 \rightarrow \mathrm{L}+1 \\
\mathrm{H} \rightarrow \mathrm{L}+3\end{array}$ & $\begin{array}{l}62 \\
24\end{array}$ \\
\hline \multirow[t]{4}{*}{$\mathrm{C} 2$} & $\mathrm{~S}_{1}$ & 2.87 & 435 & 0.2938 & $\mathrm{H} \rightarrow \mathrm{L}$ & 97 \\
\hline & $\mathrm{S}_{3}$ & 3.78 & 328 & 0.1196 & $\begin{array}{l}\mathrm{H}-1 \rightarrow \mathrm{L} \\
\mathrm{H}-3 \rightarrow \mathrm{L}\end{array}$ & $\begin{array}{l}86 \\
6\end{array}$ \\
\hline & $\mathrm{S}_{6}$ & 5.01 & 248 & 0.6778 & $\begin{array}{l}\mathrm{H} \rightarrow \mathrm{L}+1 \\
\mathrm{H}-1 \rightarrow \mathrm{L} \\
\mathrm{H}-3 \rightarrow \mathrm{L}\end{array}$ & $\begin{array}{l}77 \\
8 \\
8 \\
\end{array}$ \\
\hline & $\mathrm{S}_{8}$ & 5.24 & 237 & 0.1734 & $\begin{array}{l}\mathrm{H} \rightarrow \mathrm{L}+2 \\
\mathrm{H}-3 \rightarrow \mathrm{L}\end{array}$ & $\begin{array}{l}83 \\
8\end{array}$ \\
\hline \multirow[t]{5}{*}{ C3 } & $\mathrm{S}_{1}$ & 4.24 & 292 & 0.1447 & $\begin{array}{l}\mathrm{H} \rightarrow \mathrm{L} \\
\mathrm{H}-1 \rightarrow \mathrm{L}+1\end{array}$ & $\begin{array}{l}86 \\
8\end{array}$ \\
\hline & $\mathrm{S}_{3}$ & 4.90 & 253 & 0.5688 & $\begin{array}{l}\mathrm{H} \rightarrow \mathrm{L}+1 \\
\mathrm{H} \rightarrow \mathrm{L}+2 \\
\mathrm{H}-1 \rightarrow \mathrm{L} \\
\mathrm{H}-1 \rightarrow \mathrm{L}+2\end{array}$ & $\begin{array}{l}45 \\
21 \\
15 \\
9\end{array}$ \\
\hline & $\mathrm{S}_{4}$ & 5.22 & 238 & 0.1517 & $\begin{array}{l}\mathrm{H}-1 \rightarrow \mathrm{L}+2 \\
\mathrm{H}-1 \rightarrow \mathrm{L} \\
\mathrm{H} \rightarrow \mathrm{L}+2 \\
\mathrm{H} \rightarrow \mathrm{L}+1\end{array}$ & $\begin{array}{l}72 \\
13 \\
6 \\
5\end{array}$ \\
\hline & $\mathrm{S}_{5}$ & 5.46 & 227 & 0.9586 & $\begin{array}{l}\mathrm{H} \rightarrow \mathrm{L}+2 \\
\mathrm{H}-1 \rightarrow \mathrm{L} \\
\mathrm{H}-1 \rightarrow \mathrm{L}+1 \\
\mathrm{H}-1 \rightarrow \mathrm{L}+2 \\
\mathrm{H} \rightarrow \mathrm{L}+1\end{array}$ & $\begin{array}{l}55 \\
15 \\
8 \\
8 \\
7\end{array}$ \\
\hline & $\mathrm{S}_{7}$ & 5.71 & 217 & 0.2460 & $\begin{array}{l}\mathrm{H}-1 \rightarrow \mathrm{L}+2 \\
\mathrm{H}-2 \rightarrow \mathrm{L} \\
\mathrm{H} \rightarrow \mathrm{L}+2 \\
\mathrm{H} \rightarrow \mathrm{L}+6\end{array}$ & $\begin{array}{l}49 \\
18 \\
15 \\
5 \\
\end{array}$ \\
\hline
\end{tabular}




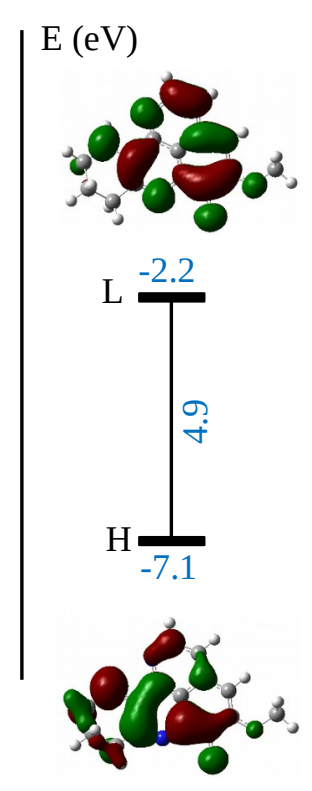

C1
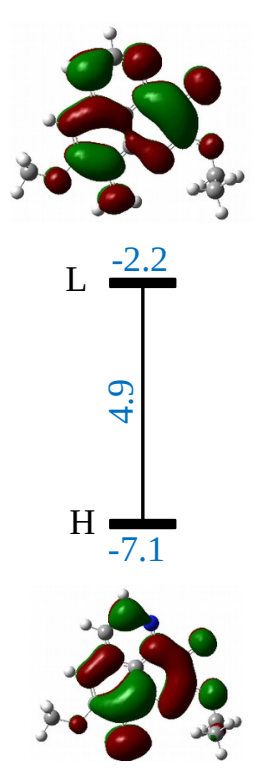

C2

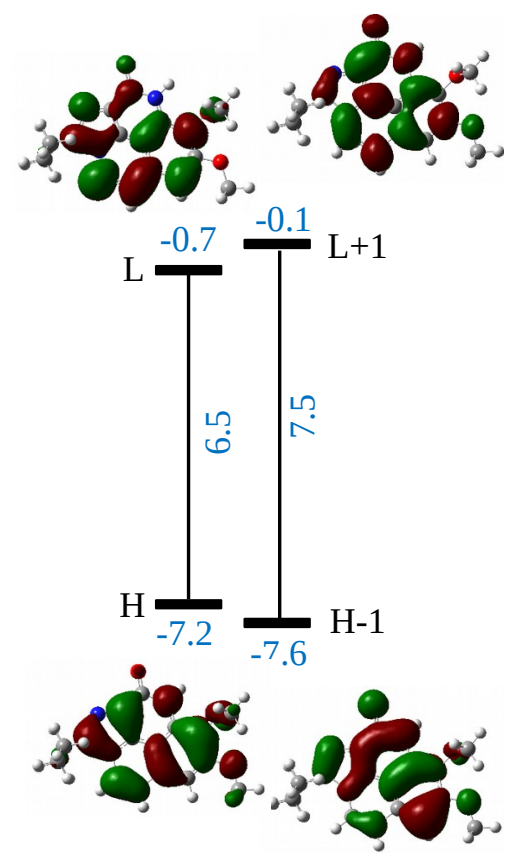

C3

Figure 8. The energy gap and energy levels of the frontier molecular orbitals which participated to the lowest electronic transition of C1-C3. The result is obtained at the TD-DFT/M05-2X/6-311++G(d,p) level in MeOH (IEF-PCM).

\section{Conclusions}

The antioxidant activities of three aaptamines (C1, C2 and C3) extracted from sponges was investigated in the gas phase and water using DFT method according to four mechanisms: HAT, SET, PL and RAF. First, all of these investigated compounds exhibited the best antioxidant activity via RAF mechanism, for which antioxidant potential is classified in the increasing order $\mathbf{C 2}<\mathbf{C 1}<\mathbf{C 3}$ for $\mathrm{HOO}^{\circ}$ and $\mathbf{C} 3<\mathbf{C 2}<\mathbf{C 1}$ for $\mathrm{HO}^{\circ}$ free radical scavenging activity. Furthermore, HAT mechanism is elucidated as the second competitive mechanism, in particularly for $\mathrm{HO}^{\bullet}$ quenching and in water. Thermodynamically, the antioxidant activities via four studied processes are in the decreasing order as follows: RAF $>$ HAT $>$ SET $>$ PL (gas) and HAT $>$ RAF $>$ SET $>$ PL (water). Kinetic calculation shows that the HAT mechanism is the most favorable path for $\mathrm{HOO}^{\bullet}$ scavenging in water with $\mathbf{C 1}$ while the RAF is more competitive with $\mathbf{C 2}$ and $\mathbf{C 3}$. Second, all three aaptamine derivatives exhibit spontaneous and favorable complexation with both the $\mathrm{Cu}(\mathrm{I})$ and $\mathrm{Cu}(\mathrm{II})$ hydrated ions in water. The $\mathrm{Cu}(\mathrm{II})$ ion chelating activity is classified in the increasing order: $\mathbf{C 3}<\mathbf{C 1}<\mathbf{C 2}$, whereas the $\mathrm{Cu}$ (I) complexation is in the 
reverse order: C2 $<$ C1 $<$ C3. Third, all compounds, particularly the $\mathbf{C 3}$, are effective in the UVA and UVB absorption. Within the range of our study, the M05-2X level provides the best performance for calculation of vertical excited energy using TD-DFT. These results promote aaptamine derivatives as natural antioxidant and anti-UV agents for the use in human healthcare such as in pharmaceutics and cosmetics.

\section{Acknowledgments}

This research is funded by Vietnam National Foundation for Science and Technology Development (NAFOSTED) under grant number 103.01-2019.380. The authors are grateful for the help in kinetic calculation from Dr. Thi Chinh Ngo (Duy Tan University). The authors are also grateful to the Gridchem (www.seagrid.org) for providing computer resources using the Extreme Science and Engineering Discovery Environment (XSEDE) supported by the USA National Science Foundation grant number ACI-10535. Dorra Khiri, Sonia Taamalli, Florent Louis, and Abderrahman El Bakali appreciated the support from the LABEX CaPPA (Chemical and Physical Properties of the Atmosphere), which is funded by the French National Research Agency (ANR) through the PIA (Programme d'Investissement d'Avenir) under contract ANR11-LABX-0005-01 and also the Regional Council "Hauts de France" and the "European Funds for Regional Economic Development".

\section{Conflict of interest}

The authors declare no conflict of interest.

\section{References}

1 K. Shaari, K. C. Ling, Z. Mat Rashid, T. P. Jean, F. Abas, S. M. Raof, Z. Zainal, N. H. Lajis, H. Mohamad and A. M. Ali, Mar. Drugs , 2009, 7.

2 L. K. Shubina, A. I. Kalinovsky, S. N. Fedorov, O. S. Radchenko, V. A. Denisenko, P. S. Dmitrenok, S. A. Dyshlovoy, V. B. Krasokhin and V. A. Stonik, Nat. Prod. Commun., 2009, 4, 1934578X0900400813.

3 C.-D. Pham, R. Hartmann, W. E. G. Müller, N. de Voogd, D. Lai and P. Proksch, J. Nat. Prod., 2013, 76, 103-106.

4 H. Nakamura, J. Kobayashi, Y. Ohizumi and Y. Hirata, Tetrahedron Lett., 1982, 23, 5555-5558.

5 H.-B. Yu, F. Yang, F. Sun, J. Li, W.-H. Jiao, J.-H. Gan, W.-Z. Hu and H.-W. Lin, Mar. 
Drugs , 2014, 12.

6 L. K. Shubina, A. I. Kalinovsky, S. N. Fedorov, O. S. Radchenko, V. A. Denisenko, P. S. Dmitrenok, S. A. Dyshlovoy, V. B. Krasokhin and V. A. Stonik, Nat. Prod. Commun., 2009, 4, $1934578 X 0900400813$.

7 J. J. Bowling, H. K. Pennaka, K. Ivey, S. Wahyuono, M. Kelly, R. F. Schinazi, F. A. Valeriote, D. E. Graves and M. T. Hamann, Chem. Biol. Drug Des., 2008, 71, 205-215.

8 G. Rajivgandhi, S. N. kumar, G. Ramachandran and N. Manoharan, Biocatal. Agric. Biotechnol., 2019, 17, 628-637.

9 H.-B. Yu, F. Yang, F. Sun, G.-Y. Ma, J.-H. Gan, W.-Z. Hu, B.-N. Han, W.-H. Jiao and H.-W. Lin, J. Nat. Prod., 2014, 77, 2124-2129.

10 S. A. Dyshlovoy, S. N. Fedorov, L. K. Shubina, A. S. Kuzmich, C. Bokemeyer, G. KellerVon Amsberg and F. Honecker, Biomed Res. Int., 2014, 2014, 469309.

11 S. A. Dyshlovoy, S. Venz, L. K. Shubina, S. N. Fedorov, R. Walther, C. Jacobsen, V. A. Stonik, C. Bokemeyer, S. Balabanov and F. Honecker, J. Proteomics, 2014, 96, 223-239.

12 T. Hamada, Y. Matsumoto, C.-S. Phan, T. Kamada, S. Onitsuka, H. Okamura, T. Iwagawa, N. Arima, F. Tani and C. S. Vairappan, Nat. Prod. Commun., 2019, 14, $1934578 X 19863935$.

13 C.-D. Pham, R. Hartmann, W. E. G. Müller, N. de Voogd, D. Lai and P. Proksch, J. Nat. Prod., 2013, 76, 103-106.

14 S. Takamatsu, T. W. Hodges, I. Rajbhandari, W. H. Gerwick, M. T. Hamann and D. G. Nagle, J. Nat. Prod., 2003, 66, 605-608.

15 P. De Luna, E. A. C. Bushnell and J. W. Gauld, J. Phys. Chem. A, 2013, 117, 4057-4065.

16 A. Pérez-González, A. Galano, J. R. Alvarez-Idaboy, D. X. Tan and R. J. Reiter, Biochim. Biophys. Acta - Gen. Subj., 2017, 1861, 2206-2217.

17 R. Castañeda-Arriaga, J. R. Alvarez-Idaboy and N. Mora-Diez, RSC Adv., 2016, 6, 107924-107932.

18 R. Castañeda-Arriaga, A. Pérez-González, J. R. Alvarez-Idaboy and A. Galano, Int. J. Quantum Chem., 2018, 118, e25527.

19 T. H. D. Thao, V. T. N. Dung and D. Q. Dao, Vietnam J. Chem., 2019, 57, 696-701.

20 G. Mazzone, J. Phys. Chem. A, 2019, 123, 9560-9566.

21 A. Galano, G. Mazzone, R. Alvarez-Diduk, T. Marino, J. R. Alvarez-Idaboy and N. Russo, Annu. Rev. Food Sci. Technol., 2016, 7, 335-352.

22 D. H. Truong, N. T. A. Nhung and D. Q. Dao, Comput. Theor. Chem., 2020, 1185, 112905. 
23 J. Krutmann, A. Bouloc, G. Sore, B. A. Bernard and T. Passeron, J. Dermatol. Sci., 2017, 85, 152-161.

24 J. Cadet, T. Douki, J.-L. Ravanat and P. Di Mascio, Photochem. Photobiol. Sci., 2009, 8, 903-911.

25 A. Fourtanier, D. Moyal and S. Seite, Photochem. Photobiol. Sci., 2012, 11, 81-89.

26 S. Dunaway, R. Odin, L. Zhou, L. Ji, Y. Zhang and A. L. Kadekaro, Front. Pharmacol., 2018, 9, 392.

27 M. S. Latha, J. Martis, V. Shobha, R. Sham Shinde, S. Bangera, B. Krishnankutty, S. Bellary, S. Varughese, P. Rao and B. R. Naveen Kumar, J. Clin. Aesthet. Dermatol., 2013, 6, 16-26.

28 R. Stevanato, M. Bertelle and S. Fabris, Regul. Toxicol. Pharmacol., 2014, 69, 71-77.

29 J. V Freitas, F. S. G. Praça, M. V. L. B. Bentley and L. R. Gaspar, Int. J. Pharm., 2015, 484, 131-137.

30 D. D. Peres, F. D. Sarruf, C. A. de Oliveira, M. V. R. Velasco and A. R. Baby, J. Photochem. Photobiol. B Biol., 2018, 185, 46-49.

31 S. Scalia and M. Mezzena, Photochem. Photobiol., 2010, 86, 273-278.

32 H. Masaki, J. Dermatol. Sci., 2010, 58, 85-90.

33 B. Rioux, C. Peyrot, M. M. Mention, F. Brunissen and F. Allais, Antioxidants , 2020, 9.

34 D. Q. Dao, T. T. T. Phan, T. L. A. Nguyen, P. T. H. Trinh, T. T. Van Tran, J. S. Lee, H. J. Shin and B.-K. Choi, J. Chem. Inf. Model., 2020, 60, 1329-1351.

35 M. J. Frisch, G. W. Trucks, H. B. Schlegel, G. E. Scuseria, M. A. Robb, J. R. Cheeseman, G. Scalmani, V. Barone, G. A. Petersson, H. Nakatsuji, X. Li, M. Caricato, A. V. Marenich, J. Bloino, B. G. Janesko, R. Gomperts, B. Mennucci, H. P. Hratchian, J. V. Ortiz, A. F. Izmaylov, J. L. Sonnenberg, D. Williams-Young, F. Ding, F. Lipparini, F. Egidi, J. Goings, B. Peng, A. Petrone, T. Henderson, D. Ranasinghe, V. G. Zakrzewski, J. Gao, N. Rega, G. Zheng, W. Liang, M. Hada, M. Ehara, K. Toyota, R. Fukuda, J. Hasegawa, M. Ishida, T. Nakajima, Y. Honda, O. Kitao, H. Nakai, T. Vreven, K. Throssell, J. A. Montgomery Jr, J. E. Peralta, F. Ogliaro, M. J. Bearpark, J. J. Heyd, E. N. Brothers, K. N. Kudin, V. N. Staroverov, T. A. Keith, R. Kobayashi, J. Normand, K. Raghavachari, A. P. Rendell, J. C. Burant, S. S. Iyengar, J. Tomasi, M. Cossi, J. M. Millam, M. Klene, C. Adamo, R. Cammi, J. W. Ochterski, R. L. Martin, K. Morokuma, O. Farkas, J. B. Foresman and D. J. Fox, 2016.

36 Y. Zhao, N. E. Schultz and D. G. Truhlar, J. Chem. Theory Comput., 2006, 2, 364-382.

37 A. Galano and J. R. Alvarez-Idaboy, J. Comput. Chem., 2013, 34, 2430-2445.

38 A. Galano and J. R. Alvarez-Idaboy, J. Comput. Chem., 2014, 35, 2019-2026. 
J. E. Bartmess, J. Phys. Chem., 1994, 98, 6420-6424.

40 Z. Markovic, J. Tošovic, D. Milenkovic and S. Markovic, Comput. Theor. Chem., 2016, 1077, 11-17.

41 E. Dzib, J. L. Cabellos, F. Ortíz-Chi, S. Pan, A. Galano and G. Merino, Int. J. Quantum Chem., 2019, 119, e25686.

42 Y. Okuno, Chem. - A Eur. J., 1997, 3, 212-218.

43 S. W. Benson, The foundations of chemical kinetics, Krieger Pu.b Co., Malabar, Florida, 1982.

44 R. A. Marcus, Annu. Rev. Phys. Chem., 1964, 15, 155.

45 F. C. Collins and G. E. Kimball, J. Colloid Sci., 1949, 4, 425-437.

46 M. V. Smoluchowski, Zeitschrift für Phys. Chemie, 1918, 92, 129.

47 D. G. Truhlar, J. Chem. Educ., 1985, 62, 104.

48 A. Einstein, Ann. Phys., 1905, 322, 549-560.

49 G. G. Stokes, Mathematical and Physical Papers, Cambridge University Press, 1905.

50 Y. H. Jang, L. C. Sowers, T. Çağin and W. A. Goddard, J. Phys. Chem. A, 2001, 105, 274-280.

51 G. C. Shields, Computational Approaches for the Prediction of pKa Values, CRC Press, 2013.

52 D. Jacquemin, B. Mennucci and C. Adamo, Phys. Chem. Chem. Phys., 2011, 13, 1698716998.

53 J. Tomasi, B. Mennucci and E. Cancès, J. Mol. Struct. THEOCHEM, 1999, 464, 211-226.

54 D. Farmanzadeh and M. Najafi, J. Serbian Chem. Soc., 2016, 81, 277-290.

55 T. C. Ngo, T. H. Nguyen and D. Q. Dao, J. Chem. Inf. Model., 2019, 59, 766-776.

56 L. Muñoz-Rugeles, A. Galano and J. R. Alvarez-Idaboy, Phys. Chem. Chem. Phys., 2017, 19, 15296-15309.

57 F. G. Bordwell, D. Algrim and N. R. Vanier, J. Org. Chem., 1977, 42, 1817-1819.

58 F. G. Bordwell and D. J. Algrim, J. Am. Chem. Soc., 1988, 110, 2964-2968.

59 D. R. Weinberg, C. J. Gagliardi, J. F. Hull, C. F. Murphy, C. A. Kent, B. C. Westlake, A. Paul, D. H. Ess, D. G. McCafferty and T. J. Meyer, Chem. Rev., 2012, 112, 4016-4093.

60 A. Martínez, A. Galano and R. Vargas, J. Phys. Chem. B, 2011, 115, 12591-12598.

61 F. Haber and J. Weiss, Naturwissenschaften, 1932, 20, 948-950. 
62 G. García-Díez, R. Ramis and N. Mora-Diez, ACS Omega, 2020, 5, 14502-14512.

63 J. Ortega-Castro, M. Adrover, J. Frau, J. Donoso and F. Muñoz, Chem. Phys. Lett., 2009, 475, 277-284.

64 R. Monreal-Corona, J. Biddlecombe, A. Ippolito and N. Mora-Diez, Antioxidants, 2020, 9, 674.

65 A. Martínez, R. Vargas and A. Galano, Comput. Theor. Chem., 2018, 1133, 47-50.

66 A. Martínez, R. Vargas and A. Galano, Int. J. Quantum Chem., 2018, 118, e25457.

67 A. Dreuw and M. Head-Gordon, J. Am. Chem. Soc., 2004, 126, 4007-4016. 